\title{
Community Water Fluoridation and Urinary Fluoride Concentrations in a National Sample of Pregnant Women in Canada
}

\author{
Christine Till, ${ }^{1}$ Rivka Green, ${ }^{1}$ John G. Grundy, ${ }^{1}$ Richard Hornung, ${ }^{2}$ Raichel Neufeld, ${ }^{1}$ E. Angeles Martinez-Mier, ${ }^{3}$ \\ Pierre Ayotte, ${ }^{4,5}$ Gina Muckle, ${ }^{5,6}$ and Bruce Lanphear ${ }^{7,8}$
}

${ }^{1}$ Faculty of Health, York University, Toronto, Ontario, Canada

${ }^{2}$ Pediatrics and Environmental Health, Cincinnati Children's Hospital Medical Center, Cincinnati, Ohio, USA

${ }^{3}$ School of Dentistry, Indiana University, Indianapolis, Indiana, USA

${ }^{4}$ Department of Social and Preventive Medicine, Laval University, Quebec, Quebec, Canada

${ }^{5}$ Centre de Recherche du CHU de Québec, Université Laval, Quebec, Quebec, Canada

${ }^{6}$ School of Psychology, Laval University, Quebec, Quebec, Canada

${ }^{7}$ Faculty of Health Sciences, Simon Fraser University, Vancouver, British Columbia, Canada

${ }^{8}$ Child \& Family Research Institute, BC Children's Hospital, University of British Columbia, Vancouver, British Columbia, Canada

BACKGROUND: Fluoride exposures have not been established for pregnant women who live in regions with and without community water fluoridation.

ОвJECTIVE: Our aim was to measure urinary fluoride levels during pregnancy. We also assessed the contribution of drinking-water and tea consumption habits to maternal urinary fluoride (MUF) concentrations and evaluated the impact of various dilution correction standards, including adjustment for urinary creatinine and specific gravity (SG).

METHODS: We measured MUF concentrations in spot samples collected in each trimester of pregnancy from 1,566 pregnant women in the MaternalInfant Research on Environmental Chemicals cohort. We calculated intraclass correlation coefficients (ICCs) to assess variability in MUF concentrations across pregnancy. We used regression analyses to estimate associations between MUF levels, tea consumption, and water fluoride concentrations as measured by water treatment plants.

RESUlTs: Creatinine-adjusted MUF values (mean \pm SD; milligrams per liter) were almost two times higher for pregnant women living in fluoridated regions $(0.87 \pm 0.50)$ compared with nonfluoridated regions $(0.46 \pm 0.34 ; p<0.001)$. MUF values tended to increase over the course of pregnancy using both unadjusted values and adjusted values. Reproducibility of the unadjusted and adjusted MUF values was modest (ICC range $=0.37-0.40$ ). The municipal water fluoride level was positively associated with creatinine-adjusted MUF $(\mathrm{B}=0.52,95 \% \mathrm{CI}: 0.46,0.57)$, accounting for $24 \%$ of the variance after controlling for covariates. Higher MUF concentrations correlated with numbers of cups of black $(r=0.31-0.32$ but not green tea $(r=0.04-0.06)$. Urinary creatinine and SG correction methods were highly correlated $(r=0.91)$ and were interchangeable in models examining predictors of MUF.

Conclusion: Community water fluoridation is a major source of fluoride exposure for pregnant women living in Canada. Urinary dilution correction with creatinine and SG were shown to be interchangeable for our sample of pregnant women. https://doi.org/10.1289/EHP3546

\section{Introduction}

The public health benefits associated with fluoridated dental products and optimally fluoridated drinking water are cited widely (Brunelle and Carlos 1990; CDC 2014; Featherstone 1999; Newbrun 1989; O’Mullane et al. 2016). Fluoride exposure can also cause potential adverse effects, such as dental fluorosis and skeletal fluorosis, both of which are observed at elevated fluoride exposure levels over a long period of time (Health Canada 2010). Fluoride exposure may also be neurotoxic, especially for the developing fetus (Grandjean and Landrigan 2014). Still, few developmental neurotoxicology studies have measured biomarkers of gestational fluoride exposure (Bashash et al. 2017; Valdez Jiménez et al. 2017). Instead, most studies use water fluoride concentrations (An et al. 1992; Broadbent et al. 2015; Eswar et al. 2011; Karimzade et al. 2014; Khan et al. 2015; Kundu et al. 2015; Liu et al. 2014; Trivedi et al. 2007; Xiang et al. 2003) or children's

Address correspondence to C. Till, Department of Psychology, York University, 4700 Keele St., M3J 1P3 Toronto, ON, Canada. Telephone: (416) 736-2100, ext. 20776. Email: ctill@yorku.ca

Supplemental Material is available online (https://doi.org/10.1289/EHP3546).

The authors declare they have no actual or potential competing financial interests.

Received 22 February 2018; Revised 7 September 2018; Accepted 8 September 2018; Published 10 October 2018.

Note to readers with disabilities: $E H P$ strives to ensure that all journal content is accessible to all readers. However, some figures and Supplemental Material published in EHP articles may not conform to 508 standards due to the complexity of the information being presented. If you need assistance accessing journal content, please contact ehponline@niehs.nih.gov. Our staff will work with you to assess and meet your accessibility needs within 3 working days. urinary fluoride level (Das and Mondal 2016; Fan et al. 2007; Trivedi et al. 2007) as measures of contemporaneous exposure.

Fluoride exposure is widespread in North America. Water and water-based beverages are the main sources of systemic ingestion, accounting for approximately $75 \%$ of dietary fluoride intake among adults living in communities that fluoridate their water supply in the United States (U.S. EPA 2010). Community water fluoridation (CWF) is the process of adjusting the amount of fluoride found in public drinking water to a level that provides optimal dental benefits. Nearly three-fourths of the U.S. population on community water systems receive fluoridated water (https:// www.cdc.gov/fluoridation/statistics/index.htm) compared with approximately one-third of Canadians and only 3\% of Europeans. In Canada and the United States, the optimal concentration of fluoride in drinking water is set at $0.7 \mathrm{mg} / \mathrm{L}$ to protect against tooth decay (DHHS 2015; Health Canada 2017). Other sources of fluoride include foods, dental products (e.g., toothpastes, mouth rinses), supplements, industrial emissions, and fluoridecontaining pharmaceuticals. Certain dietary products, like tea, have been identified to have high concentrations of natural fluoride (Fung et al. 1999; Malinowska et al. 2008; Waugh et al. 2016; USDA 2005).

The National Toxicology Program (NTP) at the National Institutes of Health (NRC 2006) and others (Grandjean and Landrigan 2014) have concluded that prenatal exposure to high levels of fluoride can alter neurodevelopment. Fluoride readily crosses the placenta (Forestier et al. 1990) and, in animal studies, accumulates in critical brain regions involved in learning and memory (Bhatnagar et al. 2002; Dong et al. 1997; Pereira et al. 2011). Results of a meta-analysis (Choi et al. 2012) of 27 epidemiologic studies showed that children who lived in areas 
with high-fluoride exposure had lower intelligence quotient (IQ) scores than those who lived in low-exposure areas. However, these findings are controversial because most of the studies were conducted in China where fluoride exists as a natural contaminant and exposure levels are often higher than the $0.70 \mathrm{mg} / \mathrm{L}$ "optimal" level for water fluoridation in North America. Notably, 13 of the 18 waterborne fluoride studies included in the 2012 meta-analysis consisted of fluoride concentrations of less than the maximum contaminant level goal of $4 \mathrm{ppm}$ (mean water fluoride level of $2.3 \mathrm{mg} / \mathrm{L}$ ). A more recent study (Bashash et al. 2017) conducted in a non-endemic fluorosis area in Mexico City of nearly 300 mother-child pairs demonstrated an inverse association between maternal urinary fluoride (MUF) concentration during pregnancy and child IQ.

Biomarkers of fluoride (e.g., urinary fluoride, serum fluoride) are directly correlated with fluoride exposure levels (e.g., water fluoride concentration, fluoride supplement exposures) in children (dela Cruz et al. 2008; Kumar et al. 2016; LeGeros et al. 1985; Singh et al. 2007; Zipkin et al. 1956), adults (Ahmed et al. 2012; Mansfield 1999; McClure and Likins 1951; Yadav et al. 2007; Zipkin et al. 1956), and pregnant women (Opydo-Szymaczek and Borysewicz-Lewicka 2007; Gardner et al. 1952). To our knowledge, however, no studies have directly compared urinary or serum fluoride concentrations with water fluoride concentration in pregnant women living in North America. Moreover, the impact of using urinary creatinine and urinary SG as correction standards for measuring urinary fluoride concentrations during pregnancy remains unclear.

We measured urinary fluoride concentrations during pregnancy from 1,566 women living in 10 cities across Canada and tested whether MUF concentrations were associated with sociodemographic factors, tea consumption habits, and water fluoride concentrations in public drinking water. We also examined how various methods of adjusting for urinary dilution affected the within-person reliability of MUF concentrations and the relationship of MUF concentrations to water fluoride concentration.

\section{Methods}

\section{Study Sample}

Between 2008 and 2011, Maternal-Infant Research on Environmental Chemicals (MIREC) Study staff recruited a populationbased sample of 2001 pregnant women from 10 cities across different geographical regions of Canada, 7 of which have CWF (Toronto, Hamilton, Ottawa, Sudbury, Halifax, Edmonton, Winnipeg; $n=1,259$ ) and 3 of which do not (Vancouver, Montreal, Kingston; $n=742$ ). To enhance the accuracy of fluoride exposure, we included only women who provided spot samples across all three trimesters. Women were recruited from prenatal clinics during their first trimester to participate in a longitudinal birth cohort study and provided written informed consent after the study was described to them. Participants were included if they could provide consent, communicate in English or French, were older than 18 y of age, and were at $<14$ wk of gestation. Participants were excluded if there was a known fetal abnormality, if they had any medical complications (i.e., cancer, renal disease, heart disease), or if there was known maternal alcohol or drug abuse during pregnancy. Participant recruitment and further demographic details and birth outcomes on the cohort can be found elsewhere (Arbuckle et al. 2013). Health Canada's Research Ethics Board and all participating recruitment sites approved the MIREC Study. The present study also received ethics approval from the York University Research Ethics Board in Toronto.

\section{Measure of Fluoride}

Fluoride concentrations were assessed in archived spot urine samples obtained from Trimester 1 at $11.57 \pm 1.57$ [mean \pm standard deviation(SD)] wk $(n=1,885)$, Trimester 2 at $19.11 \pm 2.39 \mathrm{wk}$ $(n=1,738)$, and Trimester 3 at $33.11 \pm 1.50 \mathrm{wk}(n=1,660)$ of gestation. Urine was collected in Nalgene ${ }^{\circledR}$ containers that were lot tested for phthalates and bisphenol A. Samples were labeled with a unique identification and barcode and then aliquoted into smaller Cryovials $^{\circledR}$ and stored at appropriate temperatures until they were shipped to the Indiana University School of Dentistry for analysis.

Fluoride concentration was analyzed using a modification of the hexamethyldisiloxane (HMDS; Sigma Chemical Co.) microdiffusion procedure of Taves (1968), as modified by MartínezMier et al. (2011). A measured and recorded volume of each sample $(0.850 \mathrm{~mL})$ was dispensed into $15-\mathrm{cm}$ plastic Petri dishes (Falcon; Fisher Scientific Co.); a sodium hydroxide $(\mathrm{NaOH}$, anhydrous; Sigma Chemical Co.) trap solution was loaded onto the Petri dish lid and after adding sulfuric acid $\left(\mathrm{H}_{2} \mathrm{SO}_{4}\right.$; Sigma Chemical Co.) saturated with HMDS, each dish was tightly sealed. Fluoride was released by acid hydrolysis and trapped in the $\mathrm{NaOH}$ trap. The fluoride-containing trap was then removed and buffered to $\mathrm{pH} 5.2$ with perchloric acid $\left(\mathrm{HClO}_{4}\right.$; Sigma Chemical Co.). The resulting solution was adjusted to a final volume of $100 \mu \mathrm{L}$ with total ionic strength buffer (TISAB II; Fisher Scientific Co.). Sets of approximately 30 samples were analyzed at any one time. Fluoride levels were determined by comparing the millivolt reading of each sample to standard curves, covering the range of the samples' values, prepared from the data for standard solutions of diffused fluoride determined at the time the samples were analyzed. Reference standard solutions were monitored daily by a quality assurance (QA) officer for stability; technicians reanalyzed, on a rotating basis, one of three standards daily. In addition, urine-based certified reference materials [PCU-F1305; Institut National de Santé Publique Québec, (INSPQ)/ Laboratoire de Toxicologie] were analyzed every 200-300 samples. Finally, the QA officer checked for errors in the sample numbers, recorded results and cell formula errors, and checked results in millivolt readings on source documents versus Microsoft Excel spreadsheets. In neutral solutions, fluoride concentrations can be measured down to $0.02 \mathrm{mg} / \mathrm{L}$ fluoride. This method has been shown to yield the highest recoveries of fluoride for undiluted samples. The precision and validity of this analysis technique has been reported elsewhere (Martínez-Mier et al. 2011). Compared with the total sample of spot urines that were available for fluoride analysis, only $0.002 \%$ (two samples) of readings was removed at the first trimester due to readings being higher than that of the highest concentration standard. No observations were removed in subsequent trimesters.

\section{Measure of Urinary Creatinine}

Urinary creatinine [CRE; in grams (g creatinine)] was measured using colorimetric end-point (Jaffe) tests on an Indiko instrument (Indiko Plus; ThermoFisher Scientific). An alkaline solution of sodium picrate was used to react with creatinine in urine to form a red Janovski complex using the Mircogenics DRI ${ }^{\circledR}$ CreatinineDetect ${ }^{\circledR}$ Test. The absorbance was read at $510 \mathrm{~nm}$ on an Indiko chemistry autoanalyzer (Indiko Plus, ThermoFisher Scientific) with a detection limit of $0.069 \mathrm{mmol} / \mathrm{L}$, reporting limit of $0.23 \mathrm{mmol} / \mathrm{L}$, and reproducibility of $2.2 \%$. Analyses of creatinine levels for Trimester 1 and 2 urines were conducted at an internationally recognized toxicology lab (Institut National de Santé Publique du Québec), which is accredited by the Standards Council of Canada under ISO 17025. Analyses of creatinine levels for Trimester 3 urines were conducted by another lab overseen by 
a Health Canada scientist. Both labs completed CRE analyses for Trimester 1, and there was a very high level of agreement between the values from each lab $(r=0.95, p<0.01, n=1,477)$; because of the consistency of CRE levels across the two labs, we chose to use the available Trimester 3 CRE results analyzed by this separate lab.

\section{Correction for Variations in Urine Dilution}

To account for variations in urine dilution at the time of measurement, MUF concentrations were adjusted for either CRE or specific gravity (SG). We used different methods to correct for hydration status because there is no established standard for estimating fluoride exposure among pregnant women. We used the average MUF concentration taken over all three trimesters for all adjustment methods. The three primary correction methods included adjustment for specific gravity $\left(\mathrm{MUF}_{\mathrm{SG}}\right)$ and two methods of adjustment for creatinine (MUF $\mathrm{CRE}_{\text {_1 }}$ and $\left.\mathrm{MUF}_{\mathrm{CRE} \_2}\right)$.

\section{$M U \boldsymbol{F}_{S G}$}

The Indiana University laboratory measured SG for all urine samples. Urine samples $(\sim 2.0 \mathrm{~mL})$ were transferred to a $36 \times$ $36 \mathrm{~mm}$ weighing dish (catalog no. 08-732-112; Fisher Scientific). After performing zero setting per the instrument instruction manual, the prism head of a pen refractometer (ATAGO Co., Ltd.) was submerged into the sample and a reading was obtained and recorded. Following the SG measurements, a $0.850-\mathrm{mL}$ aliquot of each sample was then removed for fluoride analysis. All readings were conducted in a darkened room and the refractometer prism head was rinsed in deionized water after each reading. Less than $0.02 \%$ of SG values fell below the limit of detection; these values were replaced by 1.001 so that we did not lose these data points when we computed the averaged MUF concentration adjusted for SG. Ad hoc analyses were also conducted to show that the use of the imputed SG values of 1.001 did not alter the mean values for MUF adjusted for SG. MUF values were corrected for SG using Equation 1:

$$
M U F_{S G(m g / L)}=\frac{M U F_{i} \times\left(S G_{M}-1\right)}{\left(S G_{i}-1\right)}
$$

where $M U F_{S G}$ is the SG-adjusted chemical concentration (in milligrams per liter), $M U F_{i}$ is the observed chemical (fluoride) concentration, $S G_{\mathrm{i}}$ is the specific gravity of the urine sample, and $S G_{M}$ is the median SG for the cohort (Hauser et al. 2004).

\section{MUF $F_{C R E \_}$}

The first method of creatinine adjustment used Equation 2:

$$
M U F_{C R E_{-} 1(m g / g)}=M U F_{i} / C R E_{i}
$$

where $M U F_{i}$ concentration (in milligrams fluoride per gram creatinine) is the observed fluoride concentration and $C R E_{i}$ is the observed creatinine concentration for that individual. The second method of CRE adjustment that was adopted by the Early Life Exposures in Mexico to ENvironmental Toxicants (ELEMENT) study (Bashash et al. 2017; Thomas et al. 2016) was based on the following equation:

$$
M U F_{C R E \_2(m g / L)}=\left(M U F_{i} / C R E_{i}\right) \times C R E_{\text {avg }}
$$

where $M U F_{C R E_{-} 2}$ is the creatinine-adjusted fluoride concentration (in milligrams fluoride per liter), $M U F_{i}$ is the observed fluoride concentration, $C R E_{i}$ is the observed CRE concentration for that individual, and $C R E_{\text {avg }}$ is the average CRE concentration of the samples available at each trimester. This method was included in order to permit comparison with a prior study examining urinary fluoride levels in a large sample of pregnant women (Bashash et al. 2017; Thomas et al. 2016).

In addition to the three methods indicated above, we also adjusted for creatinine $\left(\mathrm{MUF}_{\mathrm{CRE} \_ \text {cov }}\right)$ and $\mathrm{SG}\left(\mathrm{MUF}_{\mathrm{SG}_{-} \text {cov }}\right)$ as covariates in regression models. This approach was recommended by Barr et al. (2005) as a method to control for confounding between factors-such as age, race, sex, and body mass index (BMI) - that may affect both exposure-related outcomes (e.g., disease risk) and variations in urine dilution.

\section{Measurement of Municipal Drinking-water Fluoride}

Municipal drinking-water reports were solicited from each city that was included in the MIREC Study. For each city included in the study, we determined water treatment plant (WTP) boundary regions and then linked the first three letters of the postal code for each participant [as reported in Trimester 3 (note that postal codes were identical between Trimester 1 and 3 for $89 \%$ of the participants)]. In some cases, participants were linked with multiple WTPs because water distribution boundaries may overlap. Water fluoride data were obtained for 1,359 of the 1,566 women (86.8\%); of these, 813 participants lived in cities with CWF and 546 lived in cities without. The primary source of drinking water (i.e., public water system or private well) was assessed by questionnaires completed by the participants during pregnancy. Of the 1,566 women with MUF and SG analyses, 1,451 who reported drinking tap water from a public source were included in the study, whereas $110(7 \%)$ who reported drinking well water, 4 $(0.2 \%)$ who reported other, and $1(<0.06 \%)$ with missing data were excluded (see Figure S1). Women who reported a drinkingwater source other than a public water supply were more likely to be white and born in Canada relative to the sample of women who reported a public drinking-water source; all other demographic characteristics were similar between the groups (see Table S1). Of the 1,451 women who reported drinking water from the tap, 1,147 (79\%) lived within the WTP distribution areas for each city sampled.

Fluoridation was defined according to current national drinking-water guidelines (Health Canada 2010), which are implemented by drinking-water authorities in the affected jurisdiction. A range of $0.6-0.8 \mathrm{mg} / \mathrm{L}$ fluoride in water is recommended by the Ministry of Health and Long-Term Care in Ontario (consistent with Health Canada's recommendation of $0.7 \mathrm{mg} / \mathrm{L}$; https://www.hc-sc.gc.ca/hl-vs/iyh-vsv/environ/fluoreng.php). In practice, fluoridated water levels may correspond to a wider range, with a maximum acceptable concentration of $1.5 \mathrm{mg} / \mathrm{L}$ (Health Canada 2010). The present study defined a nonfluoridated site as having water fluoride levels (both adjusted and natural fluoride levels) of $<0.3 \mathrm{mg} / \mathrm{L}$.

We calculated each participant's average fluoridated drinkingwater value for the duration of their pregnancy by taking the average of three quarterly means. For example, births in Quarter 1 (January, February, March) were calculated by computing the average of Quarters 3 and 4 of the year before birth and Quarter 1 of the birth year. We calculated geometric means (GMs) given the large range of water fluoride values. For participants who received water from more than one WTP, the fluoridated drinking-water value was calculated by computing the average of the three quarterly GMs from each relevant WTP (see Table S2). Some cities (e.g., Montreal) had both fluoridated and nonfluoridated zones (see sample map showing distributions for each WTP in Figure S2). Participants living in each region were coded accordingly. Finally, for cities that reported fluoride concentrations that were equivalent to the limit of detection (LOD), we used an imputed value of the LOD divided by the square root of 2 (Hornung and Reed 1990) to 
calculate the water fluoride level. Average water fluoride levels reported by the municipal WTPs during the years that the participants were in the study are provided in Table S3.

\section{Fluoride Intake}

We estimated fluoride intake via drinking-water habits and consumption of beverages that are known to be high in fluoride content by asking participants about daily water and tea (black or green) consumption. Black and green tea leaves have both been identified as natural sources of fluoride via absorption through the soil (Fung et al. 1999; Malinowska et al. 2008). Participants were asked at the first and third trimester the following question: "Since the beginning of your pregnancy, how much did you drink the following: water (number of glasses; 1 glass $=8 \mathrm{oz}$ ); regular tea (cups); green tea (number of cups; 1 cup $=6 \mathrm{oz}$ )?" Participants could answer "none" or insert a number of glasses/cups and select a frequency (day/week/month).

\section{Statistical Analyses}

We performed statistical analyses for women who had all three urine samples corresponding to each trimester using RStudio (version 1.1.383) and SAS (version 9.3; SAS Institute Inc.). We used a two-sided $\alpha=0.05$ for hypothesis testing. Because the distributions of the MUF levels were right-skewed, values were $\log _{10}$-transformed to obtain a more normal distribution.

We first calculated crude descriptive statistics for each trimester, averaged over the entire pregnancy (ignoring dilution effects) and using each of the three urinary dilution correction methods. Possible differences between the MUF levels for the different trimesters were evaluated with an analysis of variance (ANOVA) test. To assess the reliability of MUF levels over the course of pregnancy, we calculated partial correlation coefficients (adjusted for covariates) between each trimester and for each MUF measurement $\left(\mathrm{MUF}_{\mathrm{SG}}, \mathrm{MUF}_{\mathrm{CRE}_{1} 1}, \mathrm{MUF}_{\mathrm{CRE}_{-} 2}\right)$ to examine whether the method of accounting for urine dilution influenced the results. In addition, we calculated intraclass correlation coefficients (ICCs), and their 95\% confidence intervals (CIs). The ICC can be interpreted as a measure of test-retest reliability and uses a pooled mean and standard deviation to center and scale each variable. Values can range from 0 (no reproducibility) to 1 (perfect reproducibility). As a final step, we computed Pearson correlation coefficients to examine the relationship between each of the methods for adjusting for $\log _{10}$-transformed MUF concentration, averaged over the pregnancy.

Covariates of interest were based on literature review (Buzalaf and Whitford 2011; Buzalaf et al. 2015) and consultation with fluoride experts on factors that may influence fluoride metabolism and intake or creatinine (Gerchman et al. 2009). These variables included prepregnancy BMI, maternal age, mother's smoking status (current smoker vs. former or never smoked), alcohol consumption (no alcohol, $<1$ alcoholic beverage per month, $\geq 1$ alcoholic beverage per month), caffeine consumption ( $\geq 1$ caffeinated beverage per day vs. did not drink caffeinated beverage), time of urine sample and time since last void (data only available for Trimesters 1 and 3), maternal education (high school or less, some college, college university degree), annual household income (less than vs. more than $\$ 70,000$ Canadian), and race (white vs. other). Covariates were chosen based on inclusion criteria where $p$ values fell below 0.2 or changed the regression coefficient by more than $10 \%$ for the association between the covariate and MUF. Covariates that reached these criteria were prepregnancy BMI (available for $99 \%$ of the total sample), maternal age, and mother's smoking status. We used Pearson correlations to examine the associations between average $\log _{10}$-transformed MUF concentration and these three covariates. We also used Pearson correlations to examine the associations between numbers of glasses of water and cups of green and black tea consumed (using averaged data collected at Trimesters 1 and 3) with average $\log _{10}$-transformed MUF concentration. We included these variables in the final models because they are sources of fluoride. We also used Pearson correlations to examine the relationship between MUF $\log _{10}$-transformed values (both averaged and trimester-specific) and time-dependent spot sampling variables (i.e., time since last void and time at void). Next, we used one-way analysis of covariance (ANCOVA) to test differences in average $\log _{10}$-transformed MUF by residential CWF status, adjusted for covariates. To ensure that multivariate interactions between covariates were not contributing to our findings, we then examined a propensity score matching algorithm in a supplemental analysis (Rosenbaum and Rubin 1983) to match the two groups on the covariates and any multivariate interactions that may exist. This approach used logistic regression to first predict the probability of all people belonging to one group. Then, a second step matched individuals from one group to those in the other based on the probability scores. Thus, individuals that contribute to an unequal match between groups were removed and the $n$ between groups was equated. Given our large sample size, the reduction in $n$ between groups was not a concern. It was more important to show that this procedure and the analyses including everyone provided converging evidence for our conclusions.

Finally, we used linear regression analyses to examine the association between the average $\log _{10}$-transformed MUF concentrations and sources of fluoride-related variables (e.g., WTP fluoride levels, number of cups of tea drunk), with and without covariates. Hierarchical regression was first used to assess the relative contribution of WTP fluoride concentrations on MUF concentration after controlling for all covariates and the other sources of fluoride. Next, we conducted forward regression to examine whether any variables other than water fluoride concentrations were contributing significantly to the model. Separate regression models were run for each method of accounting for urinary dilution of MUF concentration. We also conducted secondary analyses adjusted for urinary dilution by modeling urinary creatinine and SG at each trimester as a timedependent covariate. The best dilution standard was deemed to be the one that had the highest partial $R^{2}$ value and beta coefficient for WTP fluoride levels regressed on the MUF level.

\section{Results}

Of the women who had at least one valid measure of MUF level, $1,566(81.6 \%)$ women had a urinary spot sample for all three trimesters, whereas 418 women were excluded because they had $<3$ samples (including 215, 137, and 66 women with 2, 1 , and 0 urine samples, respectively) (Table 1). Of the women who had samples for all three trimesters, the mean age was $32.3 \mathrm{y}$ $(\mathrm{SD}=4.94$, range 28-48 y). Eighty-six percent of the sample identified as white, and $81 \%$ of the women were born in Canada. Almost 96\% were married or common-law, and almost $85 \%$ had a college diploma or university degree. At the time of pregnancy, $86 \%$ of the women were employed either full or part time. Specific gravity was measured in all 1,566 urine samples, whereas urine creatinine was available for 1,236 of the 1,566 (78.9\%) urine samples (Table 1). Women who were excluded from the analyses of $\mathrm{MUF}_{\mathrm{SG}}$ because they had $<3$ samples $(n=418)$ tended to have a lower level of education and household income, a slightly higher BMI, and were more likely to be younger, unmarried, and to smoke as compared with the women who were included in the analysis (Table 1). Women who were 
Table 1. Characteristics of women with data from three trimesters that were included in the analyses of $\mathrm{MUF}_{\mathrm{SG}}(n=1,566)$ and $\mathrm{MUF}_{\mathrm{CRE}-1}(n=1,236)$ and women who were excluded because they had data from two or fewer trimesters. Values are mean \pm SD or $n$ (\%) unless otherwise indicated.

\begin{tabular}{|c|c|c|c|c|c|c|}
\hline \multirow[b]{2}{*}{ Variables } & \multicolumn{3}{|c|}{$\mathrm{MUF}_{\mathrm{SG}}$} & \multicolumn{3}{|c|}{$\mathrm{MUF}_{\mathrm{CRE} \_1}$} \\
\hline & Included $^{a}$ & Excluded & $p$-Value $^{b}$ & Included & Excluded & $p$-Value $^{b}$ \\
\hline$n$ & $1,566^{c}$ & $418^{c}$ & - & $1,236^{c}$ & $748^{c}$ & - \\
\hline Age of mother at enrollment (y) & $32.3 \pm 4.9$ & $31.7 \pm 5.5$ & 0.03 & $32.3 \pm 4.9$ & $32.0 \pm 5.3$ & 0.20 \\
\hline White & $1,347(86.0)$ & $304(84.0)$ & \multirow[t]{2}{*}{0.32} & $1,074(86.9)$ & $577(83.4)$ & \multirow[t]{2}{*}{0.03} \\
\hline Other & $219(14.0)$ & $58(16.0)$ & & $162(13.1)$ & $115(16.6)$ & \\
\hline \multicolumn{7}{|l|}{ Marital Status } \\
\hline Married or common law & $1,501(95.9)$ & $335(92.5)$ & 0.008 & $1,182(95.6)$ & 654 (94.5) & 0.27 \\
\hline Born in Canada & $1,269(81.0)$ & $300(82.9)$ & \multirow[t]{2}{*}{0.42} & $1,011(81.8)$ & $558(80.6)$ & \multirow[t]{2}{*}{0.53} \\
\hline Born outside of Canada & $297(19.0)$ & $62(17.1)$ & & $225(18.2)$ & $134(19.4)$ & \\
\hline \multicolumn{7}{|l|}{ Maternal Education } \\
\hline High school or less & $124(7.9)$ & $44(12.2)$ & \multirow[t]{4}{*}{0.005} & $95(7.7)$ & $73(10.6)$ & \multirow[t]{4}{*}{0.007} \\
\hline Some college & $78(5.0)$ & $22(6.1)$ & & $59(4.8)$ & $41(5.9)$ & \\
\hline College diploma & $356(22.7)$ & $97(26.8)$ & & $274(22.2)$ & $179(25.9)$ & \\
\hline University degree & $1,007(64.3)$ & $199(55.0)$ & & $807(65.3)$ & $398(57.6)$ & \\
\hline \multicolumn{7}{|l|}{ Employment status at time of pregnancy } \\
\hline \multicolumn{7}{|l|}{ Net household income } \\
\hline Net household income $>\$ 70,000 \mathrm{CDN}$ & $1,067(70.8)$ & $217(64.2)$ & \multirow[t]{2}{*}{0.02} & $839(70.4)$ & $445(68.1)$ & \multirow[t]{2}{*}{0.06} \\
\hline Net $<\$ 70,000 \mathrm{CDN}$ & $440(29.2)$ & $121(35.8)$ & & $353(29.6)$ & $208(31.9)$ & \\
\hline \multicolumn{7}{|l|}{ Smoking during pregnancy } \\
\hline Trimester 1 & $77(5.0)$ & $35(8.4)$ & 0.007 & $49(4.0)$ & $63(8.9)$ & $<0.001$ \\
\hline Trimester 3 & $69(4.4)$ & $11(2.6)$ & 0.10 & $46(3.7)$ & $34(4.8)$ & 0.37 \\
\hline
\end{tabular}

Note: BMI, body mass index; CRE, creatinine; MUF, maternal urinary fluoride; SD, standard deviation; SG, specific gravity.

${ }^{a}$ The total sample of women who had a valid value for unadjusted MUF at each trimester included two additional participants $(n=1,568)$. These two additional participants would have a negligible impact on the means shown for $\mathrm{MUF}_{\mathrm{SG}}$, and hence data are not shown for the unadjusted MUF.

${ }^{b}$ Comparisons of percentages/count data were done using the chi-square test; comparisons of means were done using Student's $t$-test. The total sample of women who had a valid value for unadjusted MUF at each trimester included two additional participants $(n=1,568)$, which had a negligible impact on the means (data not shown).

${ }^{c}$ Sample size may be lower for some of the characteristics listed in each group because of missing data.

excluded from the analyses of $\mathrm{MUF}_{\mathrm{CRE}}$ because they had $<3$ samples $(n=748)$ tended to be of nonwhite race, smoking at Trimester 1 (but not Trimester 3), and to have a slightly lower level of education and a higher prepregnancy BMI.

Of the sample of women who provided three urine samples, 114 (7.3\%) participants reported a primary drinking-water source other than the public water supply (i.e., reverse osmosis system, well water, or bottled water) in their first trimester visit; these women were excluded from the analysis, as was one participant who did not report what type of water source she used (see Table S1).

\section{Consistency of MUF Levels over Pregnancy and across Dilution Correction Methods}

MUF values increased from Trimester 1 to Trimester 3 across all methods used to correct urinary dilution (Figure 1; see also Table S4). Linear contrast tests were all highly significant $(p<0.0001)$ for all of the MUF values, suggesting a linear increase over time. MUF concentrations across each trimester of pregnancy were weakly to moderately correlated, with the correlation coefficients ranging from 0.31 to 0.52 (all $p<0.0001$ ) (Figure 2). We observed stronger correlations between measurements closer in time (e.g., T1 and T2 or T2 and T3). Correlations with T1 were lower for all of the urinary dilution adjusted methods. Overall, serial MUF measurements indicated modest reproducibility across all methods of adjustment (ICC range: 0.37-0.40). The highest ICC was observed using the $\mathrm{MUF}_{\mathrm{CRE} \_2}$ measurement $(\mathrm{ICC}=$ 0.40 ; 95\% CI: $0.36,0.43$ ). A slightly lower ICC value was observed for the unadjusted MUF value $(\mathrm{ICC}=0.37 ; 95 \% \mathrm{CI}$ : $0.34,0.40)$.

Averaging over the course of pregnancy, $\log _{10}$-transformed unadjusted MUF values were moderately correlated with SG- $(r=0.68, p<0.001)$ and CRE-adjusted MUF values $(r=0.56$, $p<0.001)$, whereas SG- and CRE-adjusted values were strongly correlated $(r=0.91, p<0.001)$. The CRE-adjustment methods were perfectly correlated $(r=1.00)$ given that $\mathrm{MUF}_{\mathrm{CRE} \_2}$ was derived by multiplying $\mathrm{MUF}_{\mathrm{CRE} \_1}$ by a constant.

MUF levels as a function of fluoridated versus nonfluoridated status. Mean MUF levels were almost two times higher among women living in fluoridated than nonfluoridated communities (Figure 3; see also Table S4), even after controlling for covariates (Table 2 ) or using propensity score matching on the covariates (see Table S5). The pattern was consistent across all three methods used to adjust for dilution status, but the mean values were highest using the creatinine correction adjustment methods, particularly MUF $\mathrm{CRE}_{\mathrm{C} \text { 1 }}$. As expected, water fluoride levels were also significantly higher among fluoridated sites than nonfluoridated sites (Table 2). Specific gravity measurements and creatinine values were also higher among pregnant women living in fluoridated as compared with nonfluoridated areas (Table 2).

\section{Correlations between MUF and Covariates}

Correlations between mean $\log _{10}$-transformed MUF concentrations for both SG- and creatinine-adjusted values and covariates are shown in Table 3. MUF $\mathrm{SG}_{\text {and }} \mathrm{MUF}_{\mathrm{CRE}}$ levels were not correlated or were very weakly associated ( $r$ values $<0.10)$ with BMI, smoking status during pregnancy, parity, level of education, and income level. Weak positive correlations were found between both $\mathrm{MUF}_{\mathrm{SG}}$ and $\mathrm{MUF}_{\mathrm{CRE}}$ concentrations and maternal age $(r=0.12$ to 0.17$)$. Moderate correlations were found between MUF $_{\text {SG }}$ and $\mathrm{MUF}_{\mathrm{CRE}}$ concentrations and water fluoride level as reported by the WTP ( $r=0.50$ to 0.52$)$; these moderate correlations remained after we multiplied the number of glasses of water 
Trimester

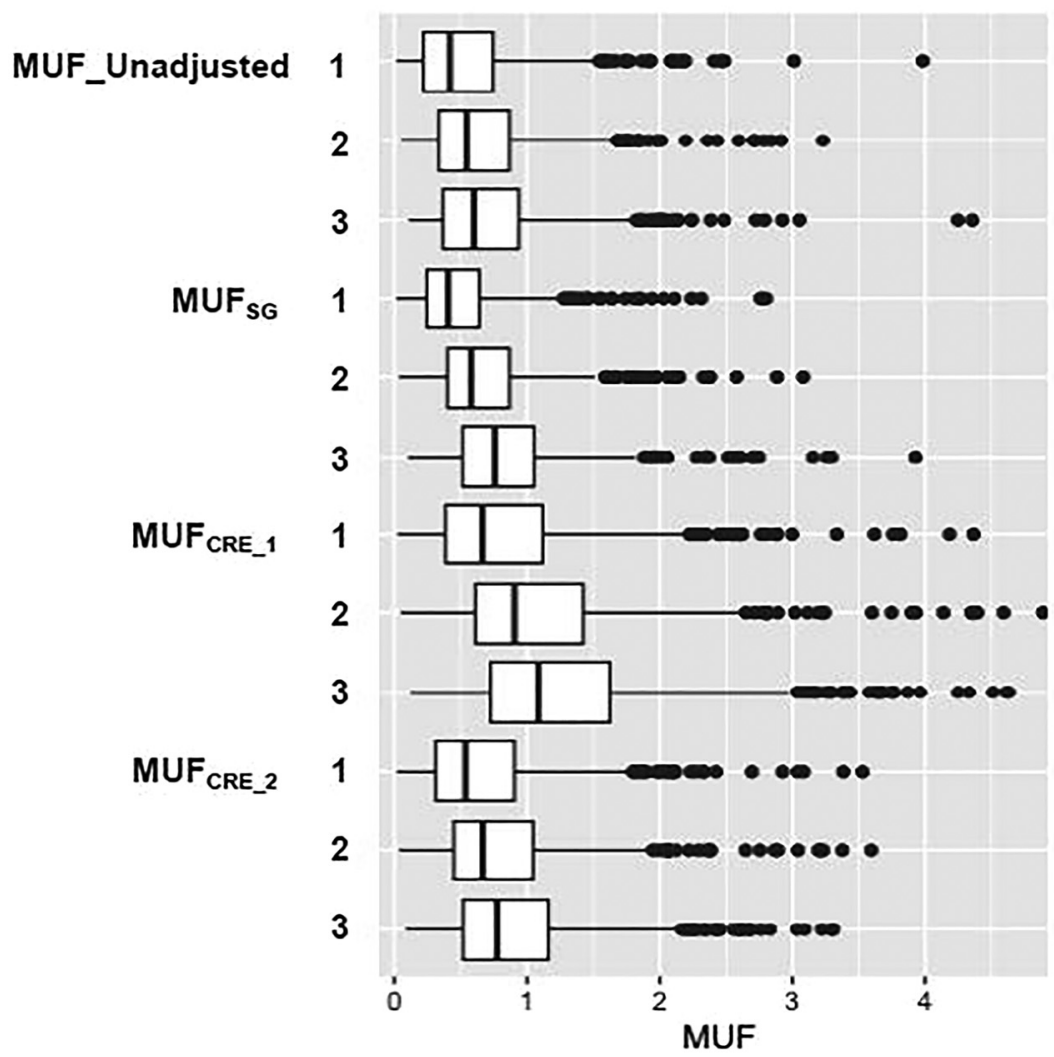

NON-FLUORIDATED

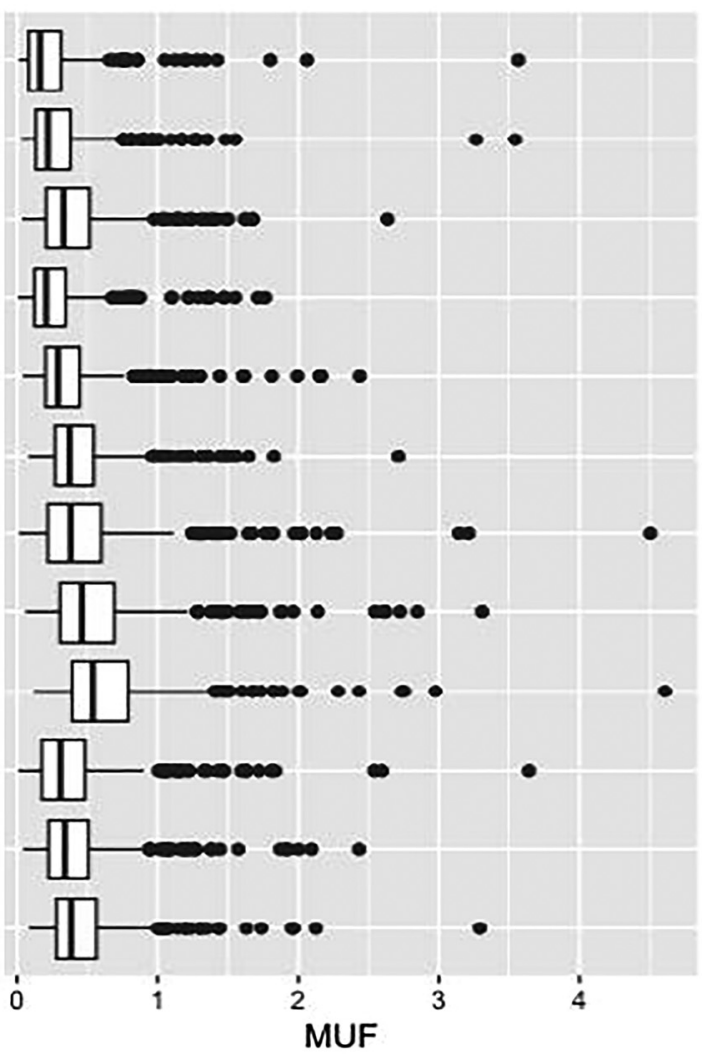

Figure 1. Fluoride concentrations by trimester in the urine of pregnant women from the MIREC cohort living in fluoridated versus nonfluoridated communities.

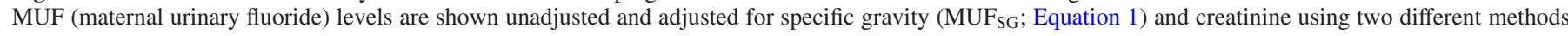
(MUF $\mathrm{CRE}_{1}$ and $\mathrm{MUF}_{\mathrm{CRE} \_2}$; Equations 2 and 3, respectively). Box plots display the upper and lower quartiles of the data; the median is marked by the vertical line inside the box. The whiskers show the 5th and 95th percentile, whereas the individual data points represent values that exceed the 95 th percentile. Box plots were produced after removing outliers defined as a MUF concentration $\geq 5$.

consumed by the estimated amount of fluoride that would be found in a 200-mL cup of tap water $(r=0.47-0.48)$. Finally, higher $\mathrm{MUF}_{\mathrm{SG}}$ and $\mathrm{MUF}_{\mathrm{CRE}}$ concentrations correlated with number of cups of black ( $r=0.31$ to 0.32$)$ but not green tea $(r=$ 0.04-0.06); the estimated amount of fluoride intake from tea consumption (factoring in fluoride from an average cup of black tea as well as from a $200-\mathrm{mL}$ cup of tap water) was also correlated with both $\mathrm{MUF}_{\mathrm{SG}}$ and $\mathrm{MUF}_{\mathrm{CRE}}$ concentrations $(r=0.16-0.18)$.

\section{Linear Regression Using Water Fluoridation Levels}

To determine whether the relationship between WTP fluoride level and MUF concentration differed as a function of the different urinary dilution correction methods that were used, we fit separate regression models using unadjusted $\mathrm{MUF}, \mathrm{MUF}_{\mathrm{SG}}$, and $\mathrm{MUF}_{\mathrm{CRE} 1 / 2}$ concentration. WTP fluoride level significantly predicted $\log _{10}$-transformed $\mathrm{MUF}_{\mathrm{SG}}$ concentrations and accounted for approximately $24 \%$ of the variance, Model 1: $R^{2}=0.24$, $F(1,1134)=361.9, p<0.0001$ (Table 4). After controlling for covariates, WTP fluoride levels remained a significant predictor of $\log _{10}$-transformed $\mathrm{MUF}_{\mathrm{SG}} \quad(\mathrm{B}=0.48, \quad 95 \% \quad \mathrm{CI}: \quad 0.43,0.53)$, accounting for approximately $22 \%$ of the variance. Model 2 was slightly stronger $(B=0.52,95 \% \mathrm{CI}: 0.46,0.57)$ than Model 1 , accounting for $24 \%$ of the variance in predicting $\log _{10}$-transformed $\mathrm{MUF}_{\mathrm{CRE}}$ concentration after adjusting for covariates (Table 4). These findings show that a $0.5-\mathrm{mg} / \mathrm{L}$ increase in water fluoride, which is roughly the difference in water fluoride level among cities that are fluoridated versus nonfluoridated in our study, would result in an increase of $73.8 \%$ and $82.0 \%$ in $\mathrm{MUF}_{\mathrm{SG}}$ and $\mathrm{MUF}_{\mathrm{CRE}}$ concentrations, respectively.

We examined models predicting log-transformed MUF (unadjusted) levels at each trimester by WTP fluoride levels before and after controlling for covariates, including the addition of urinary $\mathrm{CRE}$ and urinary $\mathrm{SG}$ (i.e., $\mathrm{MUF}_{\mathrm{CRE} \_ \text {cov }}, \mathrm{MUF}_{\mathrm{SG} \_ \text {cov }}$ ). Partial $R^{2}$ values for WTP fluoride levels ranged from 0.10 to 0.16 when creatinine was used a covariate versus 0.09 to 0.14 when SG was used a covariate (Table 5). These values were lower than the partial $R^{2}$ in Models 1 and 2 (0.22 and 0.24 , respectively), although this difference can be explained by the high correlation between CRE and SG with MUF concentration. The associations were somewhat stronger between WTP fluoride and MUF concentration for CRE than for SG as a covariate.

\section{Discussion}

We measured fluoride levels in urine samples collected during each trimester from 1,566 pregnant women living in fluoridated and nonfluoridated communities in a Canadian pregnancy cohort. We found that mean urinary fluoride values were almost two times higher for pregnant women living in fluoridated regions than for those in nonfluoridated regions (Table 2). The differences in MUF concentration remained significant after adjustment for relevant covariates. Urinary fluoride levels were significantly lower among women living in nonfluoridated regions, despite the so-called diffusion or halo effect (Griffin et al. 2001; Ripa 1993), which refers to the extension of fluoridation to residents of nonfluoridated communities as a result of foods and beverages that 
MUF (unadjusted), ICC 0.37 (95\% Cl: $0.34-0.4)$
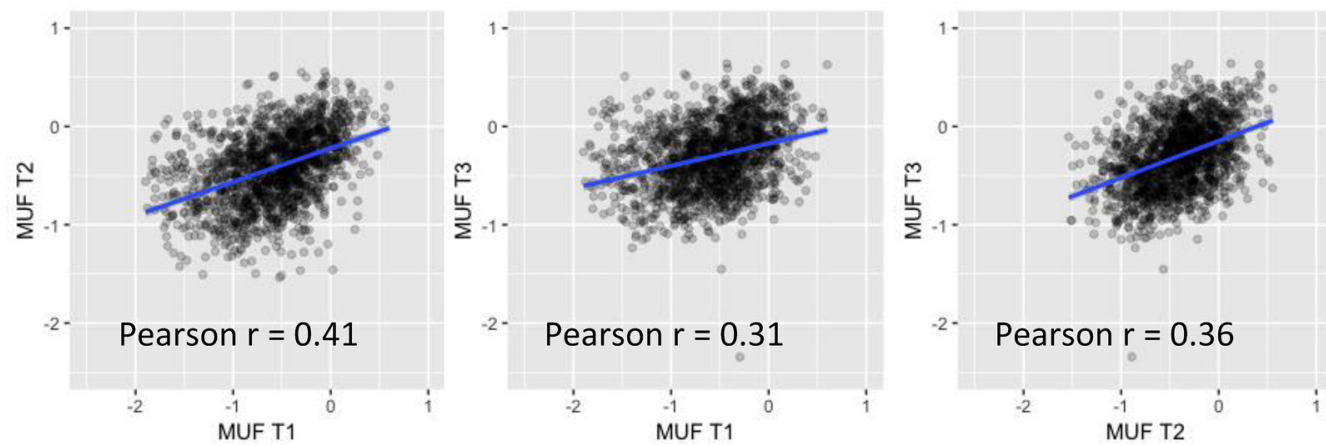

$\mathrm{MUF}_{\mathrm{SG}}, \mathrm{ICC}=0.39(95 \% \mathrm{Cl}: 0.36-0.42)$
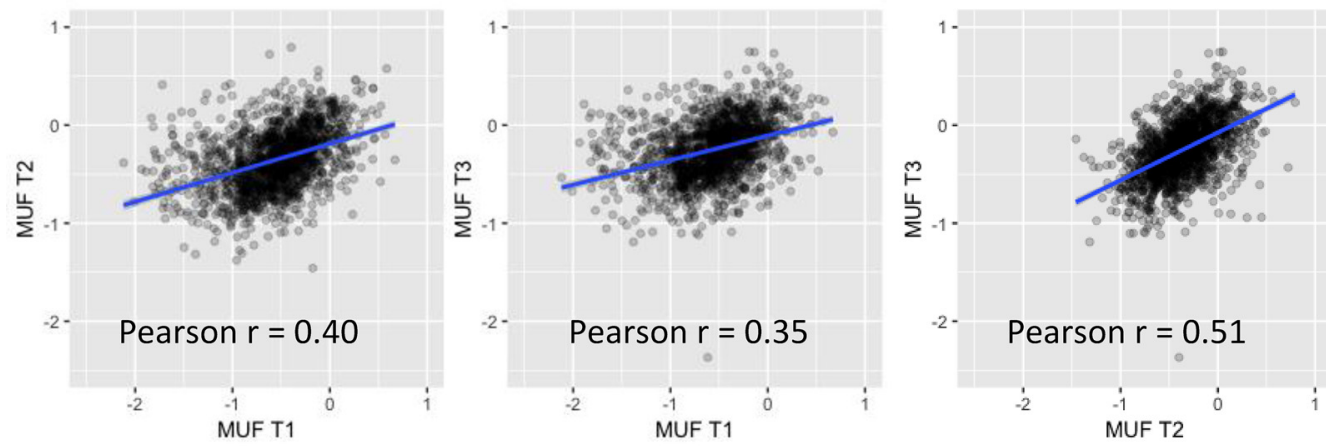

MUF $_{\mathrm{CRE}_{-} 1}, \mathrm{ICC}=0.38(95 \% \mathrm{Cl}: 0.36-0.43)$
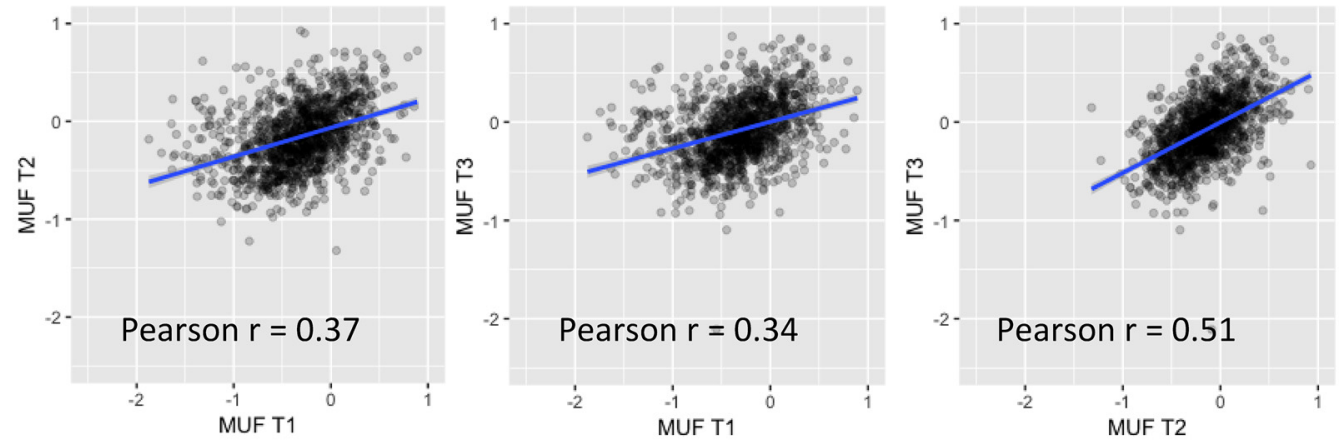

MUF $_{\text {CRE_2 },}$ ICC $=0.40(95 \% \mathrm{Cl}: 0.35-0.42)$
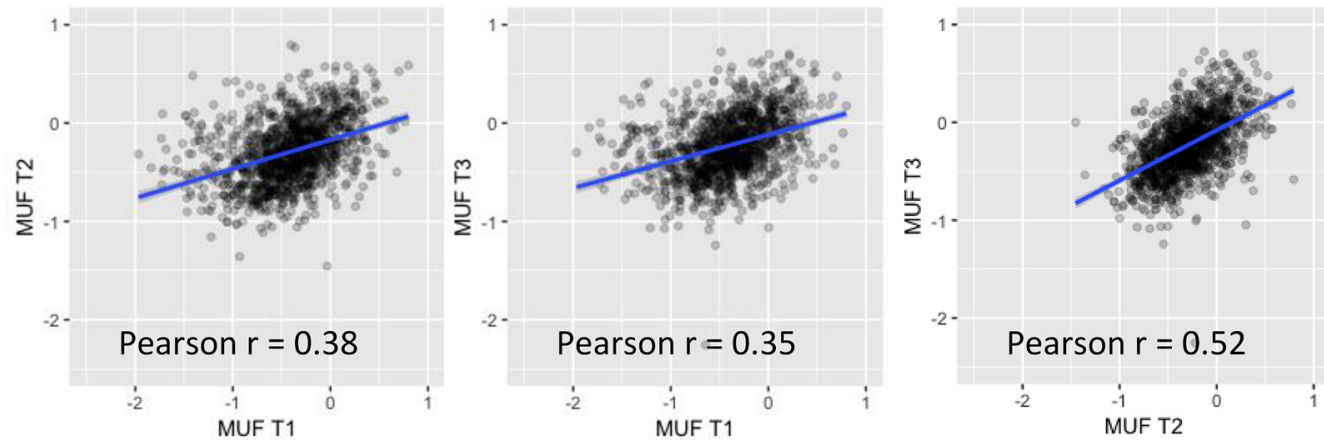

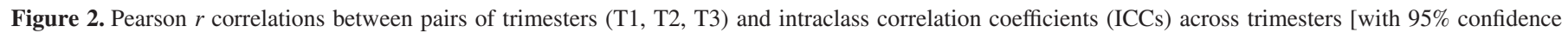

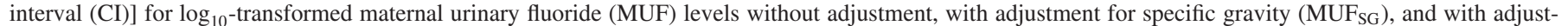

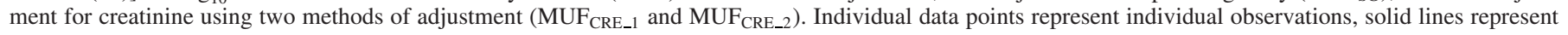
regression lines.

are commercially processed in fluoridated areas and consumed in nonfluoridated communities. Measuring fluoride exposure as a function of CWF status is therefore essential, especially given that the prevalence and severity of dental fluorosis (evidence for excessive ingestion of fluoride) is higher among youth living in fluoridated regions (Beltrán-Aguilar et al. 2010; Warren 

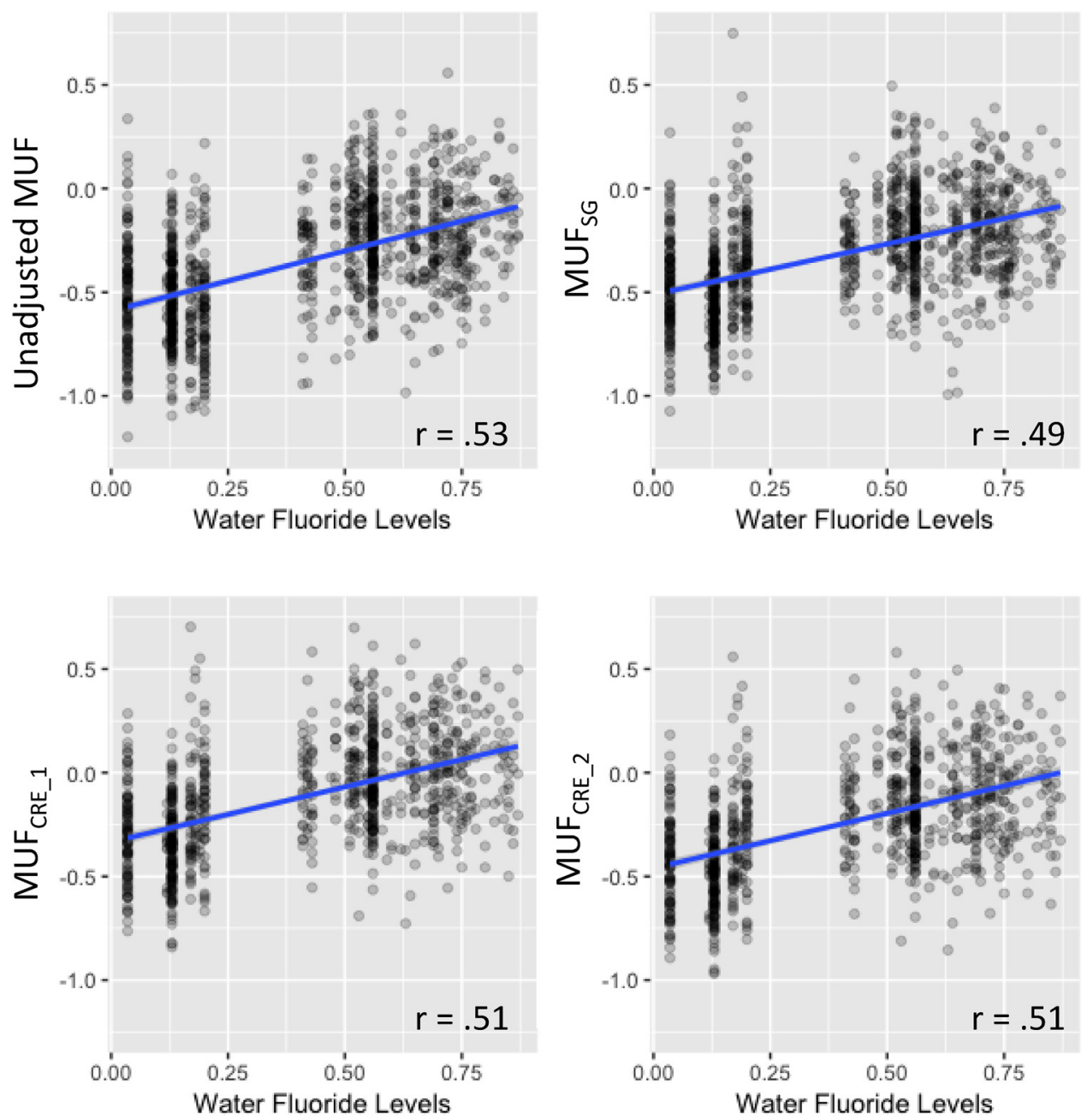

Figure 3. $\log _{10}$-transformed maternal urinary fluoride (MUF) exposure levels as a function of water treatment plant fluoride levels. MUF levels are shown unadjusted and adjusted for specific gravity $\left(\mathrm{MUF}_{\mathrm{SG}}\right)$ and creatinine using two different methods $\left(\mathrm{MUF}_{\mathrm{CRE}_{-} 1}\right.$ and $\left.\mathrm{MUF}_{\mathrm{CRE}_{2} 2}\right)$. Individual data points represent individual observations. Solid lines represent regression lines.

et al. 1999), reflecting the widespread availability of fluoride. Differences in urinary fluoride level as a function of CWF status are consistent with those reported in another Canadian sample of respondents, 3 to $79 \mathrm{y}$ of age, who participated in Cycle 2 (2009-2011) of the Chemical Health Measures Survey (CHMS) (McLaren 2016).

MUF levels increased from Trimesters 1 to 3 for all of the methods used to correct for urinary dilution, consistent with prior studies conducted in pregnant women in urine (OpydoSzymaczek and Borysewicz-Lewicka 2005; Valdez Jiménez et al. 2017) and blood plasma (Opydo-Szymaczek and Borysewicz-
Lewicka 2006). This linear increase may reflect a number of potential mechanisms that change over the course of fetal development and pregnancy, such as the higher uptake of fluoride into fetal bone in the first trimester compared with the third trimester when fetal bone tissues are mineralized. In contrast with our study, some other studies have reported decreasing levels of MUF over the course of pregnancy (Gedalia et al. 1959; Thomas et al. 2016). In the ELEMENT cohort, MUF concentrations were measured (Thomas et al. 2016) in over 500 women living in Mexico City. However, the time points included broad and overlapping intervals that were defined as early (0-26 wk), mid (15-

Table 2. Comparison of maternal urinary fluoride adjusted for covariates (BMI, maternal age, smoking status, glasses of water, as well as black and green tea consumption) as a function of residential fluoridation status. Values reported represent data from individuals who had valid urinary fluoride measurements at all three time points.

\begin{tabular}{|c|c|c|c|c|c|c|c|c|c|c|c|c|}
\hline \multirow[b]{2}{*}{ Fluoride measures } & \multicolumn{5}{|c|}{ Fluoridated } & \multicolumn{6}{|c|}{ Non-fluoridated } & \multirow[b]{2}{*}{$p$-Value } \\
\hline & $n$ & Mean & Median & $\mathrm{SD}$ & Range & $n$ & Mean & Median & SD & Range & $\overline{F \text {-Value }}$ & \\
\hline$\overline{\text { MUF_Unadjusted (mg/L) }}$ & 672 & 0.70 & 0.61 & 0.40 & $0.10-3.61$ & 464 & 0.34 & 0.28 & 0.24 & $0.06-2.17$ & 465.8 & $<0.0001$ \\
\hline $\mathrm{MUF}_{\mathrm{SG}}(\mathrm{mg} / \mathrm{L})$ & 672 & 0.71 & 0.62 & 0.38 & $0.10-3.12$ & 463 & 0.41 & 0.34 & 0.28 & $0.08-2.78$ & 347.1 & $<0.0001$ \\
\hline $\operatorname{MUF}_{\mathrm{CRE} \_2}(\mathrm{mg} / \mathrm{L})$ & 530 & 0.87 & 0.74 & 0.50 & $0.14-3.80$ & 370 & 0.46 & 0.38 & 0.34 & $0.11-3.62$ & 305.4 & $<0.0001$ \\
\hline WTP fluoride level $(\mathrm{mg} / \mathrm{L})$ & 813 & 0.61 & 0.56 & 0.11 & $0.41-0.87$ & 546 & 0.12 & 0.13 & 0.06 & $0.04-0.20$ & 8562.6 & $<0.0001$ \\
\hline SG & 729 & 1.014 & 1.013 & 0.005 & $1.002-1.030$ & 476 & 1.012 & 1.012 & 0.005 & $1.002-1.028$ & 31.29 & $<0.0001$ \\
\hline Creatinine (grams) & 536 & 6.66 & 6.17 & 3.61 & $0.93-23.84$ & 374 & 6.03 & 5.51 & 3.50 & $1.07-32.67$ & 6.75 & 0.01 \\
\hline
\end{tabular}

Note: BMI, body mass index; CRE, creatinine; MUF, maternal urinary fluoride; SD, standard deviation; SG, specific gravity; WTP, water treatment plant. 
Table 3. Pearson correlations between different derivations of $\log _{10}$-transformed MUF averaged across three trimesters.

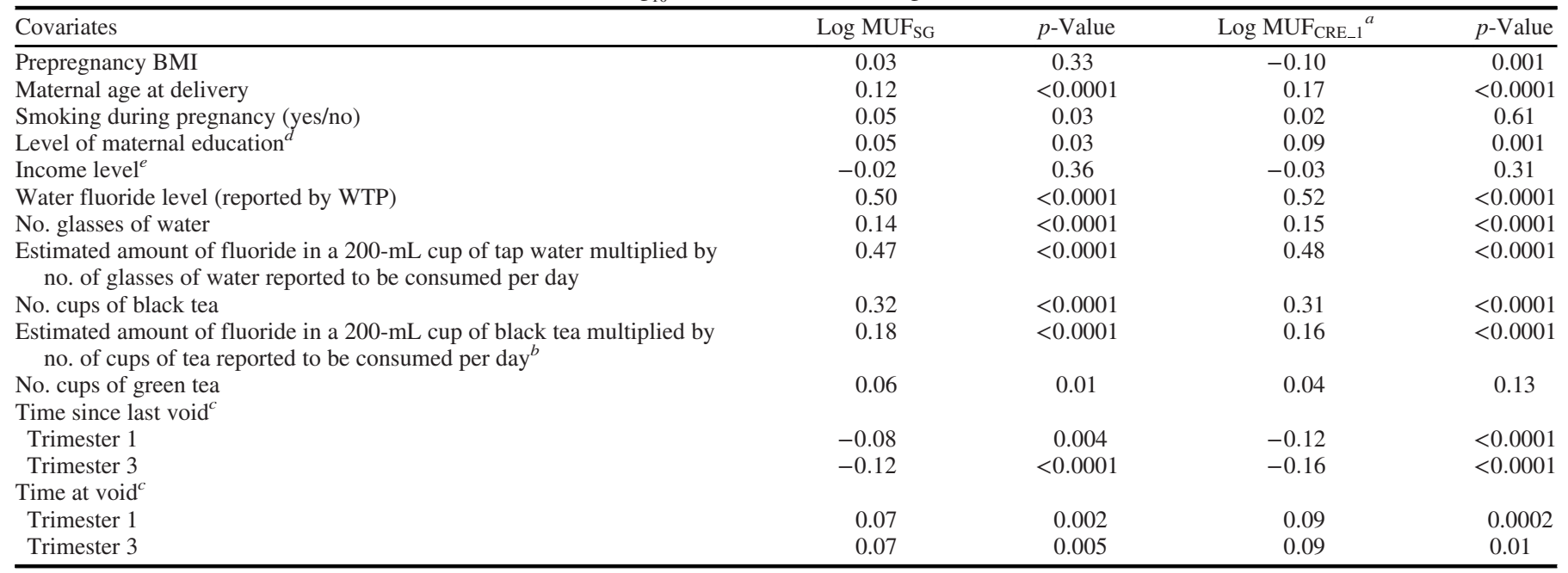

Note: BMI, body mass index; CRE, creatinine; MUF, maternal urinary fluoride; SD, standard deviation; SG, specific gravity; WTP, water treatment plant

${ }^{a}$ Data not shown for $\mathrm{MUF}_{\mathrm{CRE}_{2} 2}$ because the results were identical to $\mathrm{MUF}_{\mathrm{CRE}_{-} 1}$.

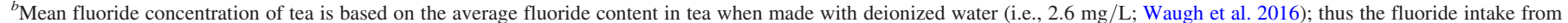

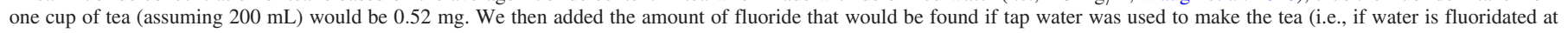
$0.7 \mathrm{mg} \mathrm{F} / \mathrm{L}$, then an additional $0.14 \mathrm{mg} \mathrm{F}$ would be added to the tea for a total of $0.66 \mathrm{mg} \mathrm{F}$ per $200-\mathrm{mL}$ cup of tea).

${ }^{c}$ Urine collection time variables were not collected at Trimester 2.

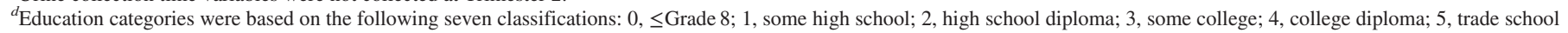
diploma; 6 , undergraduate degree, 7 , graduate degree.

${ }^{e}$ Income categories were based on the following nine classifications: $0, \leq \$ 10,000 ; 1, \$ 10,001-20,000 ; 2, \$ 20,001-30,000 ; 3, \$ 30,001-40,000 ; 4, \$ 40,001-50,000 ; 5, \$ 50,001-60,000$; 6, \$60,001-70,000; 7, \$70,001-80,000; 8, \$80,001-100,000; 9, $\geq \$ 100,000$.

37 wk), and late (22-43 wk), which may have diluted trimesterspecific effects. Moreover, only 71 of the women provided samples at all three time points and some of the women were sampled at zero weeks of pregnancy (i.e., not yet pregnant), which would inflate measurements in the early stage of pregnancy given that nonpregnant women have higher levels of urinary fluoride compared with pregnant women (OpydoSzymaczek and Borysewicz-Lewicka 2005).

We found that pregnant women who lived in fluoridated communities in Canada had mean MUF_2 creatinine-adjusted concentrations $(0.87 \mathrm{mg} / \mathrm{L}$; range: $0.14-3.80)$ that fall within a similar range as the creatinine-adjusted levels reported among pregnant women living in nonendemic fluorosis areas in Mexico City (0.91 mg/L; range: 0.02-3.67) (Thomas et al. 2016). The similarity in MUF concentrations between the Canadian and Mexican pregnancy cohorts is of scientific and public health relevance given recent findings showing an inverse association between prenatal fluoride exposure and child IQ at 4 y of age and between 6 and 12 y of age in nearly 300 mother-child pairs (Bashash et al. 2017). At the time of the publication of the paper by Bashash et al., there were no available data on urinary fluoride exposure of pregnant women exposed to fluoridated water to assess the applicability of their findings. Our results therefore provide an important comparison point. However, the Mexican population was mainly exposed to fluoride through ingestion of salt (fluoridated to $230 \mathrm{ppm}$ ), not artificially fluoridated water. This difference in fluoride source does not permit direct comparison of fluoride exposure among the two populations because we were unable to determine whether people in communities with fluoridated water had the same level of fluoride ingestion as those who consumed fluoridated salt in Mexico.

We also examined factors that could contribute to fluoride exposure or metabolism, including women's age, prepregnancy BMI, education, income level, water and tea consumption, and fluoride level of the woman's drinking-water supply. Older age was associated with higher urinary fluoride concentration, consistent with prior findings showing higher fluoride content in bone with increasing age in women (Mostafaei et al. 2015). Higher education was weakly and positively associated with urinary fluoride concentration $(r<0.10)$, whereas income level and

Table 4. Comparison of beta coefficients for dilution-adjusted MUF linear regression models. Models 1 and 2 predict $\mathrm{MUF}_{\mathrm{SG}}$ and $\mathrm{MUF}_{\mathrm{CRE} \_2}$ concentrations by water treatment plant fluoridation levels before and after controlling for covariates.

\begin{tabular}{|c|c|c|c|c|c|c|}
\hline \multirow[b]{2}{*}{ Covariates } & \multicolumn{3}{|c|}{ Model 1 Log $\mathrm{MUF}_{\mathrm{SG}}(n=1,136)$} & \multicolumn{3}{|c|}{ Model $2^{a} \log \mathrm{MUF}_{\mathrm{CRE} \_2}(n=900)$} \\
\hline & $R^{2}$ & B coefficient & $95 \% \mathrm{CI}$ & $\overline{R^{2}}$ & B coefficient & $95 \% \mathrm{CI}$ \\
\hline \multicolumn{7}{|l|}{ Unadjusted Model } \\
\hline WTP fluoride level & 0.24 & 0.49 & $0.44,0.54$ & 0.26 & 0.53 & $0.47,0.59$ \\
\hline WTP fluoride level & 0.22 & 0.48 & $0.43,0.53$ & 0.24 & 0.52 & $0.46,0.57$ \\
\hline Prepregnancy BMI & 0.00 & 0.00 & $-0.00,0.00$ & 0.01 & -0.01 & $-0.01,0.00$ \\
\hline Maternal age at delivery & 0.02 & 0.01 & $0.00,0.01$ & 0.02 & 0.01 & $0.00,0.01$ \\
\hline Smoking during pregnancy & 0.00 & 0.01 & $-0.01,0.03$ & 0.00 & -0.00 & $-0.03,0.02$ \\
\hline No. cups of green tea & 0.00 & 0.08 & $0.01,0.15$ & 0.00 & 0.06 & $-0.02,0.13$ \\
\hline
\end{tabular}

Note: BMI, body mass index; CI, confidence interval; CRE, creatinine; MUF, maternal urinary fluoride; SG, specific gravity; WTP, water treatment plant.

${ }^{a}$ Data not shown for $\mathrm{MUF}_{\mathrm{CRE} \_1}$ because the results were identical to $\mathrm{MUF}_{\mathrm{CRE} \_2}$. 
Table 5. Beta coefficients and $R^{2}$ for linear regression models predicting log-transformed MUF (unadjusted) levels by water fluoride levels before and after

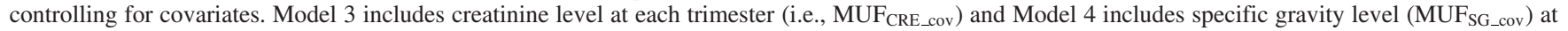
each trimester.

\begin{tabular}{|c|c|c|c|c|c|c|c|c|c|}
\hline \multirow[b]{2}{*}{ Covariates } & \multicolumn{3}{|c|}{ Log MUF_trimester1 $(n=1,317)$} & \multicolumn{3}{|c|}{ Log MUF_trimester2 $(n=1,251)$} & \multicolumn{3}{|c|}{ Log MUF_trimester3 $(n=1,203)$} \\
\hline & $R^{2}$ & B coefficient & $95 \% \mathrm{CI}$ & $R^{2}$ & B coefficient & $95 \% \mathrm{CI}$ & $R^{2}$ & B coefficient & $95 \% \mathrm{CI}$ \\
\hline Unadjusted WTP fluoride level & 0.17 & 0.75 & $0.66,0.84$ & 0.23 & 0.70 & $0.63,0.77$ & 0.13 & 0.47 & $0.40,0.54$ \\
\hline Model 3: After covariate adjustment & 0.33 & & & 0.45 & & & 0.48 & & \\
\hline Creatinine & 0.21 & 0.04 & $0.04,0.04$ & 0.25 & 0.04 & $0.04,0.04$ & 0.29 & 0.04 & $0.04,0.05$ \\
\hline WTP fluoride level & 0.10 & 0.58 & $0.50,0.66$ & 0.16 & 0.59 & $0.53,0.65$ & 0.16 & 0.50 & $0.44,0.56$ \\
\hline Prepregnancy BMI & 0.00 & -0.00 & $-0.01,0.00$ & 0.00 & -0.00 & $-0.01,0.00$ & 0.00 & -0.00 & $-0.00,0.00$ \\
\hline Maternal age at delivery & 0.01 & 0.01 & $0.00,0.01$ & 0.01 & 0.01 & $0.00,0.01$ & 0.01 & 0.01 & $0.00,0.08$ \\
\hline Smoking during pregnancy & 0.00 & 0.02 & $-0.00,0.05$ & 0.00 & 0.01 & $-0.01,0.03$ & 0.00 & 0.02 & $-0.00,0.04$ \\
\hline No. glasses of water & 0.00 & 0.01 & $0.00,0.02$ & 0.00 & 0.01 & $0.00,0.01$ & 0.00 & 0.01 & $0.00,0.01$ \\
\hline No. cups of black tea & 0.01 & 0.10 & $0.06,0.14$ & 0.03 & 0.11 & $0.08,0.14$ & 0.02 & 0.08 & $0.06,0.11$ \\
\hline No. cups of green tea & 0.00 & 0.07 & $-0.03,0.16$ & 0.00 & 0.02 & $0.04,0.04$ & 0.00 & -0.02 & $-0.09,0.05$ \\
\hline Model 4: After covariate adjustment & 0.31 & & & 0.48 & & & 0.50 & & \\
\hline SG & 0.21 & 29.35 & $26.58,32.12$ & 0.30 & 30.15 & $28.03,32.30$ & 0.32 & 29.00 & $26.83,31.16$ \\
\hline WTP fluoride level & 0.09 & 0.57 & $0.49,0.65$ & 0.14 & 0.57 & $0.51,0.62$ & 0.13 & 0.47 & $0.42,0.53$ \\
\hline Prepregnancy BMI & 0.00 & 0.00 & $-0.01,0.00$ & 0.00 & 0.00 & $-0.00,0.00$ & 0.00 & 0.00 & $-0.00,0.00$ \\
\hline Maternal age at delivery & 0.00 & 0.00 & $0.00,0.01$ & 0.01 & 0.01 & $0.00,0.01$ & 0.01 & 0.01 & $0.00,0.01$ \\
\hline Smoking during pregnancy & 0.00 & 0.02 & $-0.00,0.05$ & 0.00 & 0.01 & $-0.01,0.03$ & 0.00 & 0.02 & $0.00,0.04$ \\
\hline No. glasses of water & 0.00 & 0.01 & $0.00,0.02$ & 0.00 & 0.01 & $0.00,0.02$ & 0.01 & 0.01 & $0.01,0.02$ \\
\hline No. black cups of tea & 0.01 & 0.10 & $0.07,0.14$ & 0.03 & 0.11 & $0.09,0.14$ & 0.03 & 0.11 & $0.08,0.13$ \\
\hline No. cups of green tea & 0.00 & 0.07 & $-0.03,0.16$ & 0.00 & 0.04 & $-0.04,0.12$ & 0.00 & 0.01 & $-0.05,0.08$ \\
\hline
\end{tabular}

Note: BMI, body mass index; CI, confidence interval; COV, covariance; CRE, creatinine; MUF, maternal urinary fluoride; SG, specific gravity; WTP, water treatment plant. ${ }^{*} p<0.01$

prepregnancy BMI were not associated. The strongest correlate of $\mathrm{MUF}_{\mathrm{SG}}$ and $\mathrm{MUF}_{\mathrm{CRE}}$ concentration was water fluoride level, indicating that artificially fluoridated drinking water is a major source of fluoride intake. Specifically, for every $0.5-\mathrm{mg} / \mathrm{L}$ increase in water fluoride level, we would expect to see a 74$82 \%$ increase in urinary fluoride concentration. These findings are consistent with prior studies showing that fluoride levels in drinking water are closely related to those in urine in adults (Paez and Dapas 1983), children and adults (Zipkin et al. 1956), and pregnant women (Opydo-Szymaczek and Borysewicz-Lewicka 2005).

Black tea consumption was also a significant predictor of MUF levels, accounting for approximately 5\% of the variance. Black teas have high concentrations of natural fluoride due to the accumulation of fluoride in tea leaves from the soil (Fung et al. 1999), and the bioavailability of fluoride in tea is close to that of sodium fluoride (U.S. EPA 2010; Waugh et al. 2016). In the Republic of Ireland, where consumption of black tea is among the highest in the world per capita, the total dietary intake of fluoride from tea can exceed the upper tolerable intake limit for both adults and children (Waugh et al. 2016). In our sample, however, the contribution of tea consumption to MUF was minor compared with fluoride intake from public drinking water.

Comparison across the different methods of controlling for urinary dilution revealed several important observations. First, the unadjusted MUF concentration (fluoridated: $0.70 \mathrm{mg} / \mathrm{L}$ ) was similar with the SG-adjusted MUF concentration (fluoridated: $0.71 \mathrm{mg} / \mathrm{L}$ ) whereas both creatinine-adjustment methods produced the highest MUF concentrations (i.e., $\mathrm{MUF}_{\mathrm{CRE} 1}=1.16 \mathrm{mg} / \mathrm{g}$ and MUF $_{\text {CRE2 }}=0.87 \mathrm{mg} / \mathrm{L}$ ). Second, ICC values for consistency across trimesters were slightly higher when correction methods were used (either SG- or CRE-adjustment ratios) relative to no adjustment for variations in urine dilution. The ICC values between SG and creatinine were about the same (0.39 vs. 0.40$)$, suggesting that the two urinary dilution correction factors are interchangeable. Notably, the ICC in the present study was considerably higher than that reported in a Mexican study of pregnant women (i.e., ICC $=0.25$ ) (Thomas et al. 2016), which is likely related to the tight control of sampling at each time point in the present study and our larger sample size. Moreover, the correlation between $\mathrm{MUF}_{\mathrm{SG}}$ and $\mathrm{MUF}_{\mathrm{CRE} 1 / 2}$ concentration was high $(r=0.91)$, suggesting minimal variability between these two correction factors. Third, WTP fluoride level regressed on MUF concentration revealed only a slight advantage for the model, adjusting for urinary creatinine, as compared with SG $\left(R^{2}: 0.35\right.$ vs. 0.33$)$. These findings suggest that both correction standards are appropriate methods, with MUF concentration adjusted for creatinine being slightly stronger in terms of predicting water fluoride level. The same pattern was revealed when creatinine was added as a covariate to the model as compared with $\mathrm{SG}$ as a covariate.

Our ability to compare the urinary fluoride data with an external source of fluoride (public drinking water) is an important strength of the study. It is notable that minimum and maximum concentrations of fluoride in public drinking-water supplies differed substantially across cities and from year to year (see Table S3). Water fluoride concentrations were lower in 2011-2012 than in 2008-2010. To reduce time-varying changes in water fluoride data, our methods carefully matched water fluoride data with the 9-month period that overlapped with each woman's pregnancy. Our ability to take the average of repeated (in most cases daily) fluoride measurements from each WTP outweighs individual measurement of fluoride from the water tap in the home. WTPs that did not add fluoridation chemicals to public drinking-water supplies did not measure fluoride levels as frequently as the sites that added fluoridation chemicals. However, it is unlikely that the reduced frequency of testing fluoride levels affected our results given that the range of exposure levels was much lower in nonfluoridated areas.

There are several limitations of this study. First, overnight fasting or 24-h urine samples are considered to be the optimal dosimeter for measuring chronic fluoride exposure (WHO 2014). In contrast, the present study measured the concentration of fluoride in a spot urine sample that did not control for recent fluoride ingestion. Urinary fluoride concentration does not measure total exposure (intake) nor did we estimate the 24-h daily urinary fluoride excretion level, which would require multiplying our fluoride:creatinine ratio by a standard creatinine value (not established to our 
knowledge for each trimester of pregnancy). A spot urine sample is limited due to diurnal variations and the influence of diet (e.g., high vegetable intake associated with higher fluoride excretion) or intake of high-fluoride foods or beverages immediately before sample collection. In general, the measurement of urinary fluoride concentration may be influenced by the rapid elimination of fluoride from the body (biologic half life of $\sim 6 \mathrm{~h}$ ) (Whitford 1994), urinary $\mathrm{pH}$ levels (Buzalaf et al. 2015), as well as variation in creatinine excretion by muscle mass, age, sex, and other factors (Barr et al. 2005; Aylward et al. 2015). Assessment of fluoride during pregnancy introduces additional challenges because many physiological changes (e.g., maternal bone metabolism) are occurring that can affect the interpretation of urinary fluoride analyses (Andra et al. 2015). To enhance our measurement, we therefore measured urinary fluoride at three time points, providing a more sensitive measurement of MUF concentration than if only one measurement were used. We only included participants who had valid fluoride measurements at each trimester in the analysis in order to control for trimester-related differences in urinary fluoride level. The modest ICC for MUF concentration in the present study suggests that exposure to fluoride (through typical water/beverage consumption habits and dental product use) occurred throughout the day in our sample, which in turn, minimized the degree of within- and between-subject variation. This notion is further supported by the relatively weak correlations between both time since last void and time at void and MUF concentration. Indeed, strong correlations ( $r=0.87-0.94)$ have been reported between the fluoride:creatinine ratio on a morning spot urine sample and fluoride excretion in a 24-h urine sample for preschool children (Villa et al. 2010; Zohouri et al. 2006), indicating that adjustment for urinary dilution approximates a 24-h biomarker. A second limitation is that the MIREC Study is not a nationally representative sample of the Canadian population of pregnant women. Nonetheless, the MIREC Study, which involves women from 10 major cities across Canada, is the largest study to date assessing fluoride exposures in pregnant women. Third, water fluoride concentrations were assigned to each woman based on the aggregation of quarterly GMs and matched to the woman's postal codes at the third trimester. This method may have introduced some variability if the pregnancy period did not align exactly with each quarter or if the woman moved her residence to a new WTP zone during the pregnancy. We noted that $11 \%$ of women had different postal codes between trimesters, although we presume some of these women moved within the same WTP zone. It should also be noted that variability in our water fluoride measurement may have been introduced by combining water fluoride data across multiple municipal drinking-water systems when there was overlap in the distribution systems, as found in Toronto. However, the mean water fluoride values were similar across these overlapping WTPs (i.e., mean water fluoride values ranging within $\pm 0.10 \mathrm{mg} / \mathrm{L}$ of each other). Finally, information about oral hygiene product use, topical fluoride procedures, or consumption of certain foods (e.g., shellfish) and other beverages (e.g., coffee, juices) may represent other important sources of fluoride but were not measured in the present study.

In summary, the modest ICC across serial time points and the strong relationship between MUF concentration and WTP fluoride levels supports the biomarker potential of urinary fluoride concentration in pregnant women, using either SG or CRE to account for urine dilution. Given the widespread exposure to fluoride and recent findings (Bashash et al. 2017) showing reductions in child IQ with gestational exposure to fluoride, the present study is an important step in quantifying fluoride exposure, patterns of exposure, and major sources of fluoride exposure in pregnant women. Research is urgently needed to determine whether prenatal exposure to fluoride contributes to neurodevelopmental outcomes in the offspring of these women.

\section{Acknowledgments}

The authors gratefully acknowledge N. Lupien, S. Bastien, and R.-L. McMaster and the MIREC Study Coordinating Staff for their administrative support; T. Arbuckle for her review of our manuscript as the Knowledge Translation representative for the Maternal-Infant Research on Environmental Chemicals (MIREC) study; A. Leblanc from the Institut National de Santé Publique Québec (INSPQ) for measuring the urinary creatinine; C. Buckley, F. Lippert, and P. Chandrappa for their analysis of urinary fluoride at the Indiana University School of Dentistry; and J. Minnery from Public Health Ontario for his valuable engineering advice regarding water fluoridation. The authors are also grateful to the staff affiliated with the community water treatment plants who helped to provide water fluoride data for this study.

This study was funded by a grant from the National Institutes of Health/National Institute of Environmental Health Science (NIH/NIEHS) (grant R21ES027044). The MIREC Study was supported by the Chemicals Management Plan at Health Canada, the Ontario Ministry of the Environment, and the Canadian Institutes for Health Research (grant MOP-81285).

\section{References}

Ahmed I, Rafique T, Hasan SK, Khan N, Khan MH, Usmani TH. 2012. Correlation of fluoride in drinking water with urine, blood plasma, and serum fluoride levels of people consuming high and low fluoride drinking water in Pakistan. Fluoride 45(4):336-340.

An J, Mei S, Liu A, Fu Y, Wang Q, Hu LLZ, et al. 1992. The effects of high fluoride on the intelligence level of primary and secondary students. Chin $\mathrm{J}$ Control Endemic Dis 7(2):93-94.

Andra SS, Austin C, Wright RO, Arora MM. 2015. Reconstructing pre-natal and early childhood exposure to multi-class organic chemicals using teeth: towards a retrospective temporal exposome. Environ Int 83:137-145, PMID: 26134987, https://doi.org/10.1016/j.envint.2015.05.010.

Arbuckle TE, Fraser WD, Fisher M, Davis K, Liang CL, Lupien N, et al. 2013. Cohort profile: the maternal-infant research on environmental chemicals research platform. Paediatr Perinat Epidemiol 27(4):415-425, PMID: 23772943, https://doi.org/ 10.1111/ppe.12061.

Aylward LL, Hays SM, Vezina A, Deveau M, St-Amand A, Nong A. 2015. Biomonitoring Equivalents for interpretation of urinary fluoride. Regul Toxicol Pharmacol 72(1):158-167, PMID: 25863192, https://doi.org/10.1016/j.yrtph.2015. 04.005 .

Barr DB, Wilder LC, Caudill SP, Gonzalez AJ, Needham LL, Pirkle JL. 2005. Urinary creatinine concentrations in the U.S. population: implications for urinary biologic monitoring measurements. Environ Health Perspect 113(2):192-200, PMID: 15687057, https://doi.org/10.1289/ehp.7337.

Bashash M, Thomas D, Hu H, Martinez-Mier EA, Sanchez BN, Basu N, et al. 2017. Prenatal fluoride exposure and cognitive outcomes in children at 4 and 6-12 years of age in Mexico. Environ Health Perspect 125(9):097017, PMID: 28937959, https://doi.org/10.1289/EHP655.

Beltrán-Aguilar ED, Barker L, Dye B. 2010. Prevalence and severity of dental fluorosis in the United States, 1999-2004. NCHS Data Brief 53:1-8, PMID: 21211168.

Bhatnagar M, Rao P, Jain S, Bhatnagar R. 2002. Neurotoxicity of fluoride: neurodegeneration in hippocampus of female mice. Indian J Exp Biol 40(5):546-554, PMID: 12622200 .

Broadbent JM, Thomson WM, Ramrakha S, Moffitt TE, Zeng J, Foster Page LA, et al. 2015. Community water fluoridation and intelligence: prospective study in New Zealand. Am J Public Health 105(1):72-76, PMID: 24832151, https://doi.org/ 10.2105/AJPH.2013.301857.

Brunelle JA, Carlos JP. 1990. Recent trends in dental caries in U.S. children and the effect of water fluoridation. J Dent Res 69(2_suppl):723-727, https://doi.org/ $10.1177 / 00220345900690$ S141

Buzalaf CP, Leite ADL, Buzalaf MAR. 2015. Fluoride Metabolism. In Fluoride: Chemistry, Analysis, Function and Effects. Preedy VR, ed. Cambridge, UK:Royal Society of Chemistry, 54-72.

Buzalaf, MAR, Whitford GM. 2011. Fluoride intake, metabolism and toxicity. In: Fluoride and the Oral Environment. Vol. 22. Buzalaf MAR, ed. Basel, Switzerland:Karger, 20-36. 
CDC (Centers for Disease Control and Prevention). 2014. Water fluoridation data \& statistics. Monitoring fluoridation in the United States. https://www.cdc.gov/ fluoridation/statistics/ [accessed 15 November 2017].

Choi AL, Sun G, Zhang Y, Grandjean P. 2012. Developmental fluoride neurotoxicity: a systematic review and meta-analysis. Environ Health Perspect 120(10):13621368, PMID: 22820538, https://doi.org/10.1289/ehp.1104912.

Das K, Mondal NK. 2016. Dental fluorosis and urinary fluoride concentration as a reflection of fluoride exposure and its impact on IQ level and BMI of children of Laxmisagar, Simlapal Block of Bankura District, W.B., India. Environ Monit Assess 188(4):218-232, PMID: 26960765, https://doi.org/10.1007/ s10661-016-5219-1.

dela Cruz GG, Rozier RG, Bawden JW. 2008. Fluoride concentration in dentin of exfoliated primary teeth as a biomarker for cumulative fluoride exposure. Caries Res 42(6):419-428, PMID: 18832828, https://doi.org/10.1159/000159605.

DHHS (U.S. Department of Health and Human Services Federal Panel on Community Water Fluoridation). 2015. U.S. public health service recommendation for fluoride concentration in drinking water for the prevention of dental caries. Public Health Rep 130(4):318-314, PMID: 26346489, https://doi.org/10.1177/003335491513000408.

Dong Z, Wan C, Zhang X, Liu J. 1997. Determination of the contents of amino acid and monoamine neurotransmitters in fetal brains from a fluorosis endemic area. J Guiyang Med Coll 18(4):241-245.

Eswar P, Nagesh L, Devaraj CG. 2011. Intelligence quotients of 12-14 year old school children in a high and a low fluoride village in India. Fluoride 14(3):168-172.

Fan Z, Dai H, Bai A, Li P, Ro L, Li G, et al. 2007. The effect of high fluoride exposure on the level of intelligence in children. Environ Health $\mathrm{J}$ 28(10):802803.

Featherstone JDB. 1999. Prevention and reversal of dental caries: role of low level fluoride. Community Dent Oral Epidemiol 27(1):31-40, PMID: 10086924, https://doi.org/10.1111/j.1600-0528.1999.tb01989.x.

Forestier F, Daffos F, Said R, Brunet CM, Guillaume PN. 1990. The passage of fluoride across the placenta. An intra-uterine study [in French]. J Gynecol Obstet Biol Reprod (Paris) 19(2):171-175, PMID: 2182701.

Fung KF, Zhang ZQ, Wong JWC, Wong MH. 1999. Fluoride contents in tea and soil from tea plantations and the release of fluoride into tea liquor during infusion. Environ Pollut 104(2):197-205, https://doi.org/10.1016/S0269-7491(98)00187-0.

Gardner DW, Smith FA, Hodge HC, Overton DE, Feltman R. 1952. The fluoride content of placental tissue as related to the fluoride content of drinking water. Science 115(2982):208-209, PMID: 14913209, https://doi.org/10.1126/science. 115.2982.208.

Gedalia I, Brzezinski A, Bercovici B. 1959. Urinary fluoride levels in women during pregnancy and after delivery. J Dent Res 38(3):548-551, PMID: 13654605, https://doi.org/10.1177/00220345590380031701.

Gerchman F, Tong J, Utzschneider KM, Zraika S, Udayasankar J, McNeely MJ, et al. 2009. Body mass index is associated with increased creatinine clearance by a mechanism independent of body fat distribution. J Clin Endocrinol Metab 94(10):3781-3788, PMID: 19584179, https://doi.org/10.1210/jc.20082508.

Grandjean P, Landrigan PJ. 2014. Neurobehavioural effects of developmental toxicity. Lancet Neurol 13(3):330-338, PMID: 24556010, https://doi.org/10.1016/S14744422(13)70278-3.

Griffin S0, Gooch BF, Lockwood SA, Tomar SL. 2001. Quantifying the diffused benefit from water fluoridation in the United States. Community Dent Oral Epidemiol 29(2):120-129, PMID: 11300171, https://doi.org/10.1111/j.1600-0528. 2001.290206.x.

Hauser R, Meeker JD, Park S, Silva MJ, Calafat AM. 2004. Temporal variability of urinary phthalate metabolite levels in men of reproductive age. Environ Health Perspect 112(17):1734-1740, PMID: 15579421, https://doi.org/10.1289/ ehp.7212.

Health Canada. 2010. "Guidelines for Canadian Drinking Water Quality: Guideline Technical Document —Fluoride." Catalogue No. H128-1/11-647E-PDF. Ottawa, ON, Canada:Her Majesty the Queen in Right of Canada.

Health Canada. 2017. "The State of Community Water Fluoridation across Canada." Prepared by the Public Health Capacity and Knowledge Management Unity, Quebec Region for the Office of the Chief Dental Officer of Canada, Public Health Agency of Canada. https:/www.canada.ca/content/dam/hc-sc/documents/ services/publications/healthy-living/community-water-fluoridation-across-canada2017/community-water-fluoridation-across-canada-2017-eng.pdf [accessed 11 June 2018]

Hornung RW, Reed LD. 1990. Estimation of average concentration in the presence of nondetectable values. Appl Occup Environ Hyg 5(1):46-51, https://doi.org/10. 1080/1047322X.1990.10389587.

Karimzade S, Aghaei M, Mahvi AH. 2014. Investigation of intelligence quotient in 9-12-year-old children exposed to high- and low-drinking water fluoride in West Azerbaijan Province, Iran. Fluoride 47(1):9-14.

Khan SA, Singh RK, Navit S, Chadha D, Johri N, Navit P, et al. 2015. Relationship between dental fluorosis and intelligence quotient of school going children in and around Lucknow District: a cross-sectional study. J Clin Diagn Res 9(11): ZC10-5., PMID: 26673535, https://doi.org/10.7860/JCDR/2015/15518.6726.

Kumar S, Lata S, Yadav JP, Yadav JP. 2016. Relationship between water, urine and serum fluoride and fluorosis in school children of Jhajjar District Haryana, India. Appl Water Sci 7(6):3377-3384, https://doi.org/10.1007/ s13201-016-0492-2.

Kundu H, Basavaraj P, Singla A, Gupta R, Singh K, Jain S. 2015. Effect of fluoride in drinking water on children's intelligence in high and low fluoride areas of Delhi. J Indian Assoc Public Health Dent 13(2):116-121, https://doi.org/10.4103/ 2319-5932.159043.

LeGeros RZ, Glenn FB, Lee DD, Glenn WD. 1985. Some physico-chemical properties of deciduous enamel of children with and without pre-natal fluoride supplementation (PNF). J Dent Res 64(3):465-469, PMID: 3855900, https://doi.org/10. $1177 / 00220345850640031601$.

Liu F, Ma J, Zhang H, Liu P, Liu YP, Xing B, et al. 2014. Fluoride exposure during development affects both cognition and emotion in mice. Physiol Behav 124:1-7, PMID: 24184405, https://doi.org/10.1016/j.physbeh.2013.10.027.

Malinowska E, Inkielewicz I, Czarnowski W, Szefer P. 2008. Assessment of fluoride concentration and daily intake by human from tea and herbal infusions. Food Chem Toxicol 46(3):1055-1061, PMID: 18078704, https://doi.org/10.1016/.jfct.2007.10.039.

Mansfield P. 1999. The distribution of urinary fluoride concentration in the UK. Fluoride 32(1):27-32.

Martínez-Mier EA, Cury JA, Heilman JR, Katz BP, Levy SM, Li Y, et al. 2011. Development of gold standard ion-selective electrode-based methods for fluoride analysis. Caries Res 45(1):3-12, PMID: 21160184, https://doi.org/10.1159/ 000321657.

McClure FJ, Likins RC. 1951. Fluorine in human teeth studied in relation to fluorine in the drinking water. J Dent Res 30(2):172-176, PMID: 14824344, https://doi.org/10. $1177 / 00220345510300020401$.

McLaren L. 2016. Fluoridation exposure status based on location of data collection in the Canadian Health Measures Survey: is it valid? J Can Dent Assoc 82:917, PMID: 27548663

Mostafaei F, McNeill FE, Chettle DR, Wainman BC, Pidruczny AE, Prestwich WV. 2015. Measurements of fluorine in contemporary urban Canadians: a comparison of the levels found in human bone using in vivo and ex vivo neutron activation analysis. Physiol Meas 36(3):465-487, PMID: 25669130, https://doi.org/10. 1088/0967-3334/36/3/465

Newbrun E. 1989. Effectiveness of water fluoridation. J Public Health Dent 49(5):279-289, https://doi.org/10.1111/j.1752-7325.1989.tb02086.x.

NRC (National Research Council). 2006. Fluoride in Drinking Water: a Scientific Review of EPA's Standards. Washington, DC:National Academies Press.

0'Mullane DM, Baez RJ, Jones S, Lennon MA, Petersen PE, Rugg-Gunn AJ, et al. 2016. Fluoride and oral health. Community Dent Health 33(2):69-99, PMID: 27352462, https://doi.org/10.1922/CDH_37070'Mullane31.

Opydo-Szymaczek J, Borysewicz-Lewicka M. 2005. Urinary fluoride levels for assessment of fluoride exposure of pregnant women in Poznan, Poland. Fluoride 38(4):312-317.

Opydo-Szymaczek J, Borysewicz-Lewicka M. 2006. Variations in concentration of fluoride in blood plasma of pregnant women and their possible consequences for amelogenesis in a fetus. Homo 57(4):295-307, PMID: 16843463, https://doi.org/ 10.1016/j.jchb.2006.02.002.

Opydo-Szymaczek J, Borysewicz-Lewicka M. 2007. Transplacental passage of fluoride in pregnant Polish women assessed on the basis of fluoride concentrations in maternal and cord blood plasma. Fluoride 40(1):46-50.

Paez D, Dapas 0. 1983. Biochemistry of fluorosis X-comparative study of the fluoride levels in biological fluids. Fluoride 15(2):88-96.

Pereira M, Dombrowski PA, Losso EM, Chioca LR, Da Cunha C, Andreatini R. 2011 Memory impairment induced by sodium fluoride is associated with changes in brain monoamine levels. Neurotox Res 19(1):55-62, PMID: 19957215, https://doi.org/10. 1007/s12640-009-9139-5

Ripa LW. 1993. A half-century of community water fluoridation in the United States: review and commentary. J Public Health Dent 53(1):17-44, PMID: 8474047 https://doi.org/10.1111/j.1752-7325.1993.tb02666.x.

Rosenbaum PR, Rubin DB. 1983. The central role of the propensity score in observational studies for causal effects. Biometrika 70(1):41-55, https://doi.org/10. 1093/biomet/70.1.41

Singh B, Gaur S, Garg VK. 2007. Fluoride in drinking water and human urine in Southern Haryana, India. J Hazard Mater 144(1-2):147-151, PMID: 17118549, https://doi.org/10.1016/i.jhazmat.2006.10.010.

Taves DR. 1968. Separation of fluoride by rapid diffusion using hexamethyldisiloxane. Talanta 15(9):969-974, PMID: 18960390, https://doi.org/10.1016/0039-9140 (68)80097-9.

Thomas DB, Basu N, Martinez-Mier EA, Sánchez BN, Zhang Z, Liu Y, et al. 2016. Urinary and plasma fluoride levels in pregnant women from Mexico City Environ Res 150:489-495, PMID: 27423051, https://doi.org/10.1016/j.envres. 2016.06.046. 
Trivedi MH, Verma RJ, Chinoy NJ, Patel RS, Sathawara NG. 2007. Effect of high fluoride water on intelligence of school children in India. Fluoride 40(3):178-183.

U.S. EPA (U.S. Environmental Protection Agency). 2010. “Fluoride: relative source contribution analysis." EPA 820-R-10-0. Washington, DC:U.S. EPA, Health and Ecological Criteria Divsion, Office of Water.

USDA (U.S. Department of Agriculture). 2005. USDA National Fluoride Database of Selected Beverages and Foods, Release 2. Beltsville, MD:USDA, Agricultural Research Service, Beltsville Human Nutrition Research Center Nutrient Data Laboratory. https://data.nal.usda.gov/dataset/usda-national-fluoride-databaseselected-beverages-and-foods-release-2-2005 [accessed 12 June 2018].

Valdez Jiménez L, López Guzmán OD, Cervantes Flores M, Costilla-Salazar R, Calderón Henández J, Alcaraz Contreras Y, et al. 2017. In utero exposure to fluoride through drinking water and cognitive development delay in children. Neurotoxicology 59:65-70, PMID: 28077305, https://doi.org/10.1016/j.neuro.2016. 12.011.

Villa A, Anabalon M, Zohouri V, Maguire A, Franco AM, Rugg-Gunn A. 2010. Relationships between fluoride intake, urinary fluoride excretion and fluoride retention in children and adults: an analysis of available data. Caries Res 44(1):60-68, PMID: 20130402, https://doi.org/10.1159/000279325.

Warren JJ, Kanellis MJ, Levy SM. 1999. Fluorosis of the primary dentition: what does it mean for permanent teeth? J Am Dent Assoc 130(3):347-356, PMID: 10085657, https://doi.org/10.14219/jada.archive.1999.0204.
Waugh D, Potter W, Limeback H, Godfrey M. 2016. Risk assessment of fluoride intake from tea in the Republic of Ireland and its implications for public health and water fluoridation. Int J Environ Res Public Health 13(3):259, PMID: 26927146, https://doi.org/10.3390/ijerph13030259.

Whitford GM. 1994. Intake and metabolism of fluoride. Adv Dent Res 8(1):5-14, PMID: 7993560, https://doi.org/10.1177/08959374940080011001.

WHO (World Health Organization). 2014. Basic Methods for Assessment of Renal Fluoride Excretion in Community Prevention Programmes for Oral Health. Geneva, Switzerland:WHO.

Xiang Q, Liang Y, Chen L, Wang C, Chen B, Chen X, et al. 2003. Effect of fluoride in drinking water on children's intelligence. Fluoride 36(2):84-94.

Yadav AK, Kaushik CP, Haritash AK, Singh B, Raghuvanshi SP, Kansal A. 2007. Determination of exposure and probable ingestion of fluoride through tea, toothpaste, tobacco and pan masala. J Hazard Mater 142(1-2):77-80, PMID: 16979289, https://doi.org/10.1016/j.jhazmat.2006.07.051.

Zipkin I, Likins RC, McClure FJ, Steere AC. 1956. Urinary fluoride levels associated with use of fluoridated waters. Public Health Rep 71(8):767-772, PMID: 13350471 https://doi.org/10.2307/4589515.

Zohouri FV, Swinbank CM, Maguire A, Moynihan PJ. 2006. Is the fluoride/creatinine ratio of a spot urine sample indicative of 24-h urinary fluoride? Community Dent Oral Epidemiol 34(2):130-138, PMID: 16515677, https://doi.org/10.1111/j. 1600-0528.2006.00269.x 